\title{
On the relationship between responses in cloud water and precipitation to changes in aerosol
}

\author{
Z. J. Lebo ${ }^{1,2}$ and G. Feingold ${ }^{2}$ \\ ${ }^{1}$ Cooperative Institute for Research in Environmental Sciences, University of Colorado Boulder, \\ Boulder, Colorado, USA \\ ${ }^{2}$ Chemical Sciences Division, NOAA Earth System Research Laboratory, Boulder, Colorado, USA \\ Correspondence to: Z. J. Lebo (zach.lebo@noaa.gov)
}

Received: 29 April 2014 - Published in Atmos. Chem. Phys. Discuss.: 22 May 2014

Revised: 22 September 2014 - Accepted: 23 September 2014 - Published: 11 November 2014

\begin{abstract}
Climate models continue to exhibit strong sensitivity to the representation of aerosol effects on cloud reflectance and cloud amount. This paper evaluates a proposed method to constrain modeled cloud liquid water path (LWP) adjustments in response to changes in aerosol concentration $N_{\mathrm{a}}$ using observations of precipitation susceptibility. Recent climate modeling has suggested a linear relationship between relative LWP responses to relative changes in $N_{\mathrm{a}}$, i.e., $\mathrm{d} \ln \mathrm{LWP} / \mathrm{d} \ln N_{\mathrm{a}}$, and the precipitation frequency susceptibility $S_{\text {pop }}$, which is defined as the relative change in the probability of precipitation for a relative change in $N_{\mathrm{a}}$. Using large-eddy simulations (LES) of marine stratocumulus and trade wind cumulus clouds, we show that these two cloud regimes exhibit qualitatively different relationships between $\lambda$ and $S_{\text {pop }}$; in stratocumulus clouds, $\lambda$ increases with $S_{\text {pop }}$, while in trade wind cumulus, $\lambda$ decreases with $S_{\text {pop }}$. The LES-derived relationship for marine stratocumulus is qualitatively similar but quantitatively different than that derived from climate model simulations of oceanic clouds aggregated over much larger spatial scales. We explore possible reasons for variability in these relationships, including the selected precipitation threshold and the various definitions of precipitation susceptibility that are currently in use. Because aerosol-cloud-precipitation interactions are inherently small-scale processes, we recommend that when deriving the relationship between $\lambda$ and $S_{\text {pop }}$, careful attention be given to the cloud regime, the scale, and the extent of aggregation of the model output or the observed data.
\end{abstract}

\section{Introduction}

Like its predecessors, the IPCC Fifth Assessment Report (AR5; IPCC 2013) continues to point to aerosol effects on clouds as a major source of uncertainty in our predictive climate-modeling capability. Recognizing that cloud systems constantly adjust to aerosol perturbations, AR5 chose to combine both cloud albedo and liquid water path (LWP) responses to aerosol changes into one term, i.e., the effective radiative forcing associated with aerosol-cloud interactions (ERFaci). The representation of the underlying microphysical processes associated with cloud formation and albedo and precipitation modification must be improved to better quantify ERFaci. Attempts to constrain ERFaci with observations are an important part of this quantification. Early efforts (e.g., Quaas et al., 2006, 2009) used satellite-based measurements of drop concentration (or size) responses to changes in aerosol (Bréon et al., 2002) to constrain the albedo effect (Twomey, 1977). More detailed analysis using surface-based remote sensing and proxy data from cloud-resolving models pointed to the scale dependence of these relationships (McComiskey and Feingold, 2008, 2012) and called for a clear distinction between the cloud process scale and the satellite data aggregation scale before such observational constraints are applied.

In this paper, we shift attention to observational constraints on aerosol effects on cloud amount, or the "lifetime effect" (Albrecht, 1989), via precipitation modifications. The most direct approach would be to quantify $\lambda\left(=d \operatorname{lnLWP} / d \ln N_{a}\right.$, or similar); however, $\lambda$ is almost impossible to measure because of the rapid adjustments resulting from both aerosol 
and meteorological drivers. A somewhat-related quantity, precipitation susceptibility, i.e., $S_{\mathrm{o}}=-\mathrm{d} \ln R / \mathrm{d} \ln N_{\mathrm{d}}$, where $R$ is the rain rate and $N_{\mathrm{d}}$ is the droplet number concentration (Feingold and Siebert, 2009; Sorooshian et al., 2009), has been introduced as a means of quantifying the influence of aerosol changes on the ambient rain rate. Because of the high spatial variability in $R$, other definitions of precipitation susceptibility, such as the susceptibility of the probability of precipitation (POP) to changes in aerosol $\left(S_{\text {pop }}\right)$, have been proposed: $S_{\text {pop }}=-\mathrm{d} \ln \mathrm{POP} / \mathrm{d} \ln N_{\mathrm{a}}$ (e.g., Wang et al., 2012; Terai et al., 2012). Several studies have attempted to quantify $S_{\text {pop }}$ or $S_{\mathrm{o}}$ using satellite remote sensing (e.g., Sorooshian et al., 2009; L'Ecuyer et al., 2009), surface remote sensing (Mann et al., 2014), and in situ aircraft (Terai et al., 2012) observations. The values vary considerably depending on several factors, including the definition of precipitation susceptibility, averaging scale (Duong et al., 2011), phase of the cloud life cycle (Duong et al., 2011; Feingold et al., 2013), and aerosol loading (Feingold et al., 2013). There is disagreement in the literature not only on the values of $S_{\text {pop }}$ and $S_{\mathrm{o}}$ but also on how they depend on important controlling parameters, such as cloud depth and LWP. Because quantifying the precipitation susceptibility is not the focus of this paper, we refer to two values as guidance. The first, $S_{\text {pop }}=0.12$ (Wang et al., 2012), was derived from satellite remote sensing data over global oceans (based on a reflectivity threshold of $0 \mathrm{dBZ}$, equivalent to $R \approx 0.5 \mathrm{~mm}_{\text {day }}{ }^{-1}$ ). The second, $S_{\mathrm{o}} \approx 1$ (Mann et al., 2014), was calculated from surface-based remote sensing observations in the northeastern Atlantic Ocean and continental Europe with a spatial scale of approximately $600 \mathrm{~m}$ (using $1 \mathrm{~min}$ averaged data and assuming a nominal wind speed of $10 \mathrm{~m} \mathrm{~s}^{-1}$ ). Rain rates at cloud base were derived from a combination of cloud radar and lidar data. One-minute average drizzle rates as low as $0.002 \mathrm{~mm} \mathrm{day}^{-1}$ were included in their analysis.

Wang et al. (2012) proposed using measurements of $S_{\text {pop }}$ as a means of constraining LWP responses to aerosol changes in a climate model. The authors used a series of climate model simulations with the NCAR Community Atmosphere Model version 5 (CAM5) and the ECHAM5-HAM2 to derive a linear relationship between $\lambda$ and $S_{\text {pop }}$ with an intercept at approximately $(0,0)$. Interestingly, the model output from the Multiscale Modeling Framework (MMF) version of CAM5, which resolves clouds and precipitation more reliably than the standard CAM5 simulations, also conforms to this linear relationship. The authors proposed a method for constraining $\lambda$ that proceeds as follows. The output from a series of general circulation model (GCM) simulations is used to define $\lambda=f\left(S_{\text {pop }}\right)$; then, a measurement of $S_{\text {pop }}$ combined with the model-derived $f\left(S_{\mathrm{pop}}\right)$ yields an observational constraint on $\lambda$. Wang et al. (2012) showed that because $f\left(S_{\text {pop }}\right)$ has an intercept close to $(0,0)$ and the measured $S_{\text {pop }}$ is small, it follows that $\lambda$, which is the cloud LWP adjustment portion of ERFaci, is also small. However, the authors noted that more work must be performed to test these relationships

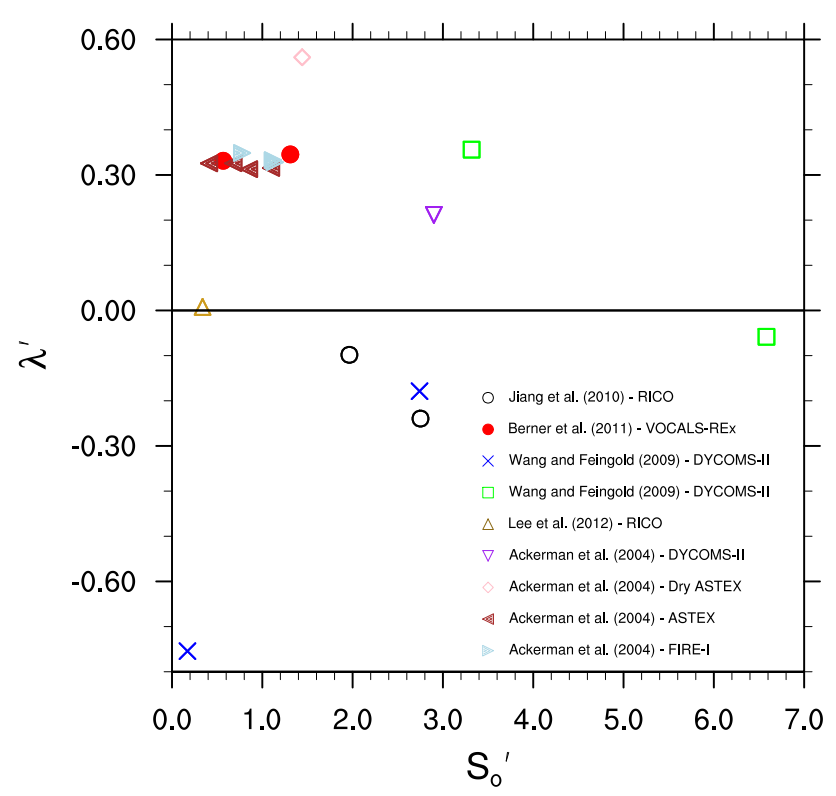

Figure 1. Scatterplot of $\lambda^{\prime}$ vs. $S_{\mathrm{o}}^{\prime}$ from previously published studies. The legend provides the reference that corresponds to each symbol. Note here that "prime" notation is used because not all of these studies provide enough detail to determine $\lambda$ and $S_{\mathrm{O}}$. Specifically, $S_{\mathrm{O}}^{\prime}$ is $\mathrm{d} \ln R / \mathrm{d} \ln N_{\mathrm{a}}$ in Jiang et al. (2010), and $\lambda^{\prime}$ is $\mathrm{d} \ln L W P / \mathrm{d} \ln N_{\mathrm{d}}$ in Berner et al. (2011). For all other references, $\lambda^{\prime}=\lambda$ and $S_{\mathrm{o}}^{\prime}=S_{\mathrm{o}}$.

in higher-resolution models. The current work directly addresses this point. Specifically, this study addresses the generality of the $\lambda-S_{\text {pop }}$ relationship. The relationship is examined at the cloud scale through analysis of previously published work and more rigorously via an analysis of largeeddy simulations (LES) of warm (liquid phase only) cloud systems. Observations of $S_{\text {pop }}$ and $S_{\mathrm{o}}$ are then used to provide LES constraints on $\lambda$; the implications for albedo susceptibility (Platnick and Twomey, 1994) are also explored.

The remainder of the paper is organized as follows. Section 2 introduces the methods used to evaluate $\lambda$ based on both the extant literature and LES. The primary results are presented and discussed in Sect. 3. Finally, the main conclusions of this work are enumerated in Sect. 4.

\section{Methods}

\subsection{Analysis of extant literature}

If there exists a robust relationship between $\lambda$ and $S_{\text {pop }}$ (or $S_{\mathrm{o}}$ ), one might expect this to emerge in the extant literature. Therefore, we surveyed published results from a wide range of studies that simulated cases based on various field campaigns. The details of these studies are listed in Table 1. In building this table (and the accompanying Fig. 1), we were faced with a lack of information regarding the rain fraction 


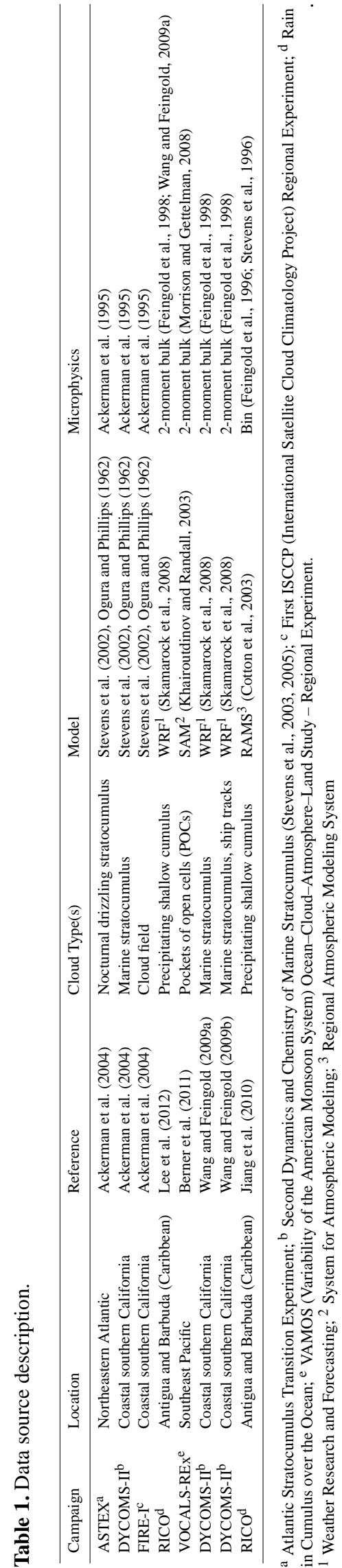

(or POP) in previously published studies. Therefore, the results are presented in terms of $S_{0}$. The potential effect of this substitution is discussed later.

\subsection{LES simulations}

Two different cloud regimes are explored: (i) stratocumulus, based on the Second Dynamics and Chemistry of Marine Stratocumulus (DYCOMS-II) Research Flight 2 (RF02), and (ii) trade wind cumulus, based on the Rain in Cumulus over the Ocean (RICO) field experiment. The two different warm cloud regimes provide the opportunity to explore the robustness of both the $\lambda-S_{\text {pop }}$ and $\lambda-S_{0}$ relationships for different cloud regimes.

\subsubsection{Stratocumulus clouds: DYCOMS-II, RF02}

A suite of 25 simulations is performed using the Weather Research and Forecasting (WRF) model to explicitly examine the relationships between $\lambda$ and $S_{\text {pop }}$ (or $S_{\mathrm{o}}$ ). For the purposes of this study, WRF is coupled with a two-moment, binemulating microphysical model that has been widely used to examine aerosol-cloud interactions (Feingold et al., 1998; Wang and Feingold, 2009a). The simulations comprise five different initial aerosol number mixing ratios (i.e., $N_{\mathrm{a}}=25$, $50,75,100$, and $125 \mathrm{mg}^{-1}$ ). Because simulations often use different initialization procedures, $N_{\mathrm{a}}$ is used interchangeably in this paper to denote both the aerosol number concentration (units of $\mathrm{cm}^{-3}$ ) and mixing ratio (units of $\mathrm{mg}^{-1}$ ). Given that the air density is approximately $1 \mathrm{~kg} \mathrm{~m}^{-3}$ for the considered domains, $1 \mathrm{mg}^{-1} \approx 1 \mathrm{~cm}^{-3}$.

While the aerosol concentration is a prognostic variable in these simulations, the shape of the distribution is invariant with time and assumed to be lognormal with a median radius of $0.2 \mu \mathrm{m}$ and a geometric standard deviation of 1.5 . The aerosol is assumed to be composed of ammonium sulfate. The supersaturation is calculated and treated prognostically in the model; droplets are formed on the aerosol particles with radii above the critical supersaturation required for activation following Köhler theory. The activated aerosol particles are removed from the aerosol population. Particles are regenerated upon evaporation of droplets assuming that one drop regenerates one aerosol particle (Mitra et al., 1992). Thus, collision-coalescence and surface rain provide an avenue for a reduction in the aerosol concentration.

For each $N_{\mathrm{a}}$, a control simulation is performed based on DYCOMS-II RF02, which readily produced drizzle (Stevens et al., 2003). The WRF-LES setup described by Yamaguchi and Feingold (2012) is used. Four additional simulations are performed to explore the sensitivity to environmental conditions and microphysical process rates, i.e., increased surface latent heat flux $\left(140 \mathrm{Wm}^{-2}\right.$, Hi-LHF), decrease surface latent heat flux $\left(46.5 \mathrm{Wm}^{-2}\right.$, Lo-LHF), increased collisioncoalescence rate $(110 \%$ of the predicted rate, Hi-CC), and 
decreased collision-coalescence rate $(80 \%$ of the predicted rate, Lo-CC).

All simulations are performed with a horizontal grid spacing of $50 \mathrm{~m}$ and a vertical grid spacing of $12 \mathrm{~m}$. The domain is $6.4 \mathrm{~km}$ by $6.4 \mathrm{~km}$ in the horizontal and $1.5 \mathrm{~km}$ in the vertical direction. A time step of $0.2 \mathrm{~s}$ is used to ensure numerical stability and convergence (see Yamaguchi and Feingold, 2012). The total simulation time is $6 \mathrm{~h}$; the initial $1 \mathrm{~h}$ of all simulations is discarded to allow sufficient time for turbulence to develop. The Rapid Radiative Transfer Model (RRTM) is used to calculate the longwave radiative fluxes. The simulations are assumed to be nocturnal (i.e., shortwave radiative fluxes are not included). The necessary model information is recorded at $1 \mathrm{~min}$ intervals, yielding nearly 5 million $x-$ $y$ pairs for each simulation. Although the decorrelation time for cloud fields has been shown to be much longer than $1 \mathrm{~min}$ (e.g., $\approx 15$ min according to McComiskey et al., 2009), the $1 \mathrm{~min}$ resolution is necessary to capture the rare, high-rainrate events.

\subsubsection{Trade wind cumulus: RICO}

The RICO simulations used in this study are adopted from Jiang et al. (2010). These simulations were performed using the Regional Atmospheric Modeling System (RAMS) version 6.0 with a bin (size-resolving) microphysics scheme (Feingold et al., 1996; Stevens et al., 1996). The aerosol treatment in these simulations is very similar to that of the stratocumulus simulations (see Sect. 2.2.1). The domain size is $25.6 \mathrm{~km} \times 25.6 \mathrm{~km} \times 6 \mathrm{~km}$ with a horizontal grid spacing of $100 \mathrm{~m}$ and vertical grid spacing of $40 \mathrm{~m}$. The Global Energy and Water Cycle Experiment Cloud System (GCSS) boundary layer working group initial sounding is modified to initiate heavier rainfall by increasing the ambient water vapor mixing ratio and decreasing the potential temperature above $1 \mathrm{~km}$. The model top is also extended in Jiang et al. (2010) to $6 \mathrm{~km}$ to allow for deeper convection. The simulations are performed for $8 \mathrm{~h}$ with five different aerosol number concentrations, namely, 100, 200, 300, 400, and $500 \mathrm{~cm}^{-3}$. As in the case of the stratocumulus simulations, model output at $1 \mathrm{~min}$ intervals is used. For additional information on these simulations, the reader is referred to Jiang et al. (2010).

\section{$2.3 \lambda$ calculation}

The LWP is first calculated for every column and for every output time by including only cloud water - consistent with Wang et al. (2012). Here, $\lambda$ is approximated as follows:

$\lambda=\frac{d \ln L W P}{d \ln N_{\mathrm{a}}} \approx \frac{\Delta \ln L W P}{\Delta \ln N_{\mathrm{a}}}=\left\langle\frac{\ln \overline{\mathrm{LWP}^{(2)}}-\ln \overline{\mathrm{LWP}^{(1)}}}{\ln N_{\mathrm{a}}^{(2)}-\ln N_{\mathrm{a}}^{(1)}}\right\rangle$,

where the overbars represent spatial (horizontal) means and the brackets represent temporal means. The superscripts correspond to low (1) and high (2) aerosol loading scenarios. For reference, all variables are also defined in Table 2 . The results are found to be qualitatively (and nearly quantitatively) insensitive to the order in which the calculations are performed, i.e., taking the temporal average of the relative differences (as in Eq. 1) or taking the relative difference of the temporal averages.

\section{$2.4 S_{\text {pop }}$ calculation}

To calculate $S_{\text {pop }}$, we first determine whether it is raining at the surface in a given grid cell and assign the grid cell $\mathrm{POP}=1$ if it is raining and $\mathrm{POP}=0$ otherwise - namely, the precipitation probability $\operatorname{POP}(t)$ as a function of time $t$ is conditional on a threshold rain rate:

$\operatorname{POP}_{i, j}^{(k)}(t)=\left\{\begin{array}{ll}1 & \text { if } R_{i, j}^{(k)}(t) \geq T_{\mathrm{h}} \\ 0 & \text { if } R_{i, j}^{(k)}(t)<T_{\mathrm{h}}\end{array}\right.$,

where $T_{\mathrm{h}}$ represents a predefined threshold in $\mathrm{mm} \mathrm{day}^{-1}, i$ and $j$ represent the indices of individual grid cells, and the superscript $k$ corresponds to the specific simulation. The surface rain rate is used for the calculations herein. Then, $S_{\text {pop }}$ is calculated similar to $\lambda$, i.e.,

$$
\begin{aligned}
S_{\text {pop }} & =-\frac{d \ln \mathrm{POP}}{d \ln N_{\mathrm{a}}} \approx-\frac{\Delta \ln \mathrm{POP}}{\Delta \ln N_{\mathrm{a}}} \\
& =-\left\langle\frac{\ln \overline{\mathrm{POP}^{(2)}}-\ln \overline{\mathrm{POP}^{(1)}}}{\ln N_{\mathrm{a}}^{(2)}-\ln N_{\mathrm{a}}^{(1)}}\right\rangle .
\end{aligned}
$$

For calculating POP, 10 thresholds are applied to $R$, ranging from $10^{-6}$ to $20 \mathrm{~mm} \mathrm{day}^{-1}$. Only a representative subset of these calculations is presented.

\section{$2.5 S_{0}$ calculation}

Here, $S_{0}$ is computed by conditionally averaging the rain rate over the aforementioned rain rate thresholds. In keeping with Feingold and Siebert (2009), the denominator is $d \ln N_{d}$ instead of $d \ln N_{a}$; therefore, we have

$$
S_{\mathrm{o}}=-\frac{d \ln R}{d \ln N_{\mathrm{d}}} \approx-\frac{\Delta \ln R}{\Delta \ln N_{\mathrm{d}}}=-\left\langle\frac{\ln \overline{R^{(2)}}-\ln \overline{R^{(1)}}}{\ln \overline{N_{\mathrm{d}}^{(2)}}-\ln \overline{N_{\mathrm{d}}^{(1)}}}\right\rangle .
$$

\section{6 $S_{0, \bmod }$ and $S_{\text {pop,mod }}$ calculations}

Two additional parameters are also computed, i.e., $S_{\mathrm{o} \text {, mod }}$ and $S_{\text {pop,mod }} ; S_{\mathrm{o} \text {, mod }}$ is the same as in Eq. (4) except that $N_{\mathrm{a}}$ replaces $N_{\mathrm{d}}$ in the denominator. Similarly, $S_{\text {pop,mod }}$ replaces $N_{\mathrm{a}}$ with $N_{\mathrm{d}}$ in the denominator of Eq. (3). These modified parameters are useful for analyzing the sensitivity of the results to the use of $N_{\mathrm{a}}$ or $N_{\mathrm{d}}$, in which the latter evolves with time and the former is used to represent the response in the system to an initial change in aerosol loading (similar to the approach used in global climate simulations). The simulations also help to examine the robustness of the results to alternative representations of precipitation susceptibility. 
Table 2. Variable names and definitions.

\begin{tabular}{|c|c|c|}
\hline Variable & Name & Description \\
\hline$R$ & Rain rate & \multirow{16}{*}{$\begin{array}{l}\int_{0}^{\infty} q_{c} \rho d z \\
\frac{d \ln \mathrm{POP}}{d \ln N_{a}} \\
\frac{d \ln R}{d \ln N_{d}} \\
\frac{d \ln \mathrm{POP}}{d \ln N_{d}} \\
\frac{d \ln R}{d \ln N_{f}} \\
\frac{d \ln \mathrm{LP}}{d \ln N_{a}}\end{array}$} \\
\hline$N_{\mathrm{a}}$ & Aerosol number concentration or mixing ratio & \\
\hline$N_{\mathrm{d}}$ & Droplet number concentration & \\
\hline$N_{\mathrm{d}, 0}$ & Droplet number concentration for cleanest simulation & \\
\hline$\rho$ & Air density & \\
\hline$z$ & Height & \\
\hline$q_{c}$ & Cloud water mixing ratio & \\
\hline POP & Probability of precipitation/precipitation frequency & \\
\hline LWP & Liquid water path & \\
\hline$S_{\text {pop }}$ & Precipitation frequency susceptibility & \\
\hline$S_{\mathrm{O}}$ & Precipitation susceptibility & \\
\hline$S_{\text {pop,mod }}$ & Modified precipitation frequency susceptibility & \\
\hline$S_{\mathrm{o}, \bmod }$ & Modified precipitation susceptibility & \\
\hline$\lambda$ & LWP susceptibility & \\
\hline$A_{\mathrm{f}}$ & Albedo susceptibility enrichment factor & \\
\hline$N_{\mathrm{d}} / N_{\mathrm{d}, 0}$ & Relative droplet number concentration & \\
\hline
\end{tabular}

\section{$2.7 \quad A_{\mathrm{f}}$ calculations}

While values of $\lambda$ that are constrained by $f\left(S_{\text {pop }}\right)$ and/or $f\left(S_{\mathrm{o}, \mathrm{mod}}\right)$ are far from certain, the estimates discussed below for the different cloud regimes can be used to estimate the potential effects of changes in aerosol loading on albedo susceptibility $A_{\mathrm{o}}^{\prime}$. We begin with the definition of $A_{\mathrm{o}}^{\prime}$ from, e.g., Feingold and Siebert (2009):

$A_{\mathrm{o}}^{\prime}=A_{\mathrm{o}}\left[1+\frac{5}{2} \frac{d \ln \mathrm{LWP}}{d \ln N_{\mathrm{d}}}+\ldots\right]$,

where $A_{\mathrm{o}}$ represents the albedo susceptibility under constant LWP conditions, i.e.,

$A_{\mathrm{o}}=\left.\frac{\partial \ln A}{\partial \ln N_{\mathrm{d}}}\right|_{\mathrm{LWP}}=\frac{1-A}{3}$.

The ellipsis on the right-hand side of Eq. (5) represents additional terms that have been excluded in this study. These terms include such effects as changes in the breadth of the drop size distribution (Feingold et al., 1997). Note that Eq. (5) is provided in terms of incremental changes in $N_{\mathrm{d}}$, whereas the LWP susceptibility, i.e., $\lambda$, is defined relative to incremental changes in $N_{\mathrm{a}}$. Therefore, we make use of a power law relationship between $N_{\mathrm{d}}$ and $N_{\mathrm{a}}$ :

$N_{\mathrm{d}} \propto N_{\mathrm{a}}^{c}$,

where $c$ is theoretically $\leq 1$. Previous studies have provided a broad range of values for $c$. For example, Shao and Liu (2009) suggested a range of 0.25 to 0.85 based on direct measurements of both polluted and clean clouds. Other studies have shown that $c$ is likely on the higher end of this range in relatively clean conditions, i.e., $N_{\mathrm{a}}<500 \mathrm{~cm}^{-3}$ (e.g., Conant et al., 2004; Twohy et al., 2005). Without being prescriptive, we choose a characteristic value of $c=3 / 4$. As a result, the relationship presented in Eq. (7) can be rewritten as

$\frac{d \ln N_{\mathrm{d}}}{d \ln N_{\mathrm{a}}}=c=\frac{3}{4}$.

Then, by rewriting Eq. (5) as

$A_{\mathrm{o}}^{\prime}=A_{\mathrm{o}}\left[1+\frac{5}{2} \frac{d \ln \operatorname{LWP}}{d \ln N_{\mathrm{a}}} \frac{d \ln N_{\mathrm{a}}}{d \ln N_{\mathrm{d}}}+\ldots\right]$,

and incorporating Eq. (8), we get

$A_{\mathrm{o}}^{\prime}=A_{\mathrm{o}}\left[1+\frac{10}{3} \lambda+\ldots\right]$.

Because we are not necessarily concerned here with the specific values of either $A_{\mathrm{o}}^{\prime}$ or $A_{\mathrm{o}}$, we define the albedo susceptibility enrichment factor $A_{\mathrm{f}}$ as follows:

$A_{\mathrm{f}}=\frac{A_{\mathrm{o}}^{\prime}}{A_{\mathrm{o}}}=\left[1+\frac{10}{3} \lambda+\ldots\right]$.

Thus, $\lambda=0.3$ corresponds to a doubling of the albedo susceptibility relative to the value under constant LWP conditions. Note that $A_{\mathrm{f}}$ can be calculated following Eq. (11) without any knowledge of the actual albedo. A further cautionary note is that because $A_{\mathrm{f}}$ is an enhancement factor, in practice it must be multiplied by the absolute albedo susceptibility $A_{\mathrm{o}}$. As the latter approaches zero, $A_{\mathrm{f}}$ has a diminishing absolute effect. Values of $A_{\mathrm{f}}$ are shown in the subsequent section alongside those of $\lambda$ for the two cloud types. Given that shortwave radiation is not treated in the simulations, these results should be regarded as qualitative. 
Previous studies have provided observational estimates of both $S_{\text {pop }}\left(0.12\right.$; Wang et al., 2012) and $S_{\mathrm{o} \text {, mod }}$ (0.66; Mann et al., 2014) using large satellite- and groundbased observational data sets, respectively. The Wang et al. (2012) value of 0.12 was derived from global ocean measurements based on CloudSat with an approximate lower rain rate threshold of $0.5 \mathrm{~mm} \mathrm{day}^{-1}$. Mann et al. (2014) analyzed data that included both marine and continental conditions and reported the precipitation susceptibility in terms of incremental changes in $N_{\mathrm{a}}$, which corresponds to $S_{\mathrm{o}}$, mod in this study. However, precipitation susceptibility has been previously defined in numerous studies relative to incremental changes in $N_{\mathrm{d}}$ (i.e., $S_{\mathrm{o}}$ ). Using Eqs. 4 and 8 , one finds that $S_{\mathrm{o}} \approx 1$ based on the findings of Mann et al. (2014).

The analysis of large-eddy simulations of stratocumulus and trade wind cumulus below will use these two observational estimates as reference points. However, we caution that the uncertainty in the relative occurrence of these two key cloud types in the observations and that we simulate only one representative case study for each cloud type, means that the comparison of a given cloud type (stratocumulus or trade wind cumulus) with the reference observations is intended solely for guidance.

\section{Results}

\subsection{Analysis of extant literature}

An initial review of the literature provides evidence that the $\lambda-S_{\text {pop }}$ (or $\lambda-S_{\mathrm{o}}$ ) relationship may not be inherently simple. First, the lack of detailed information regarding the rain fraction or POP made it impossible to determine accurate values of $S_{\text {pop }}$ from previously published modeling results. Therefore, we use $S_{\mathrm{o}}$ in our analysis of the published literature. Even with this assumption, several studies still lacked the necessary details to determine a relationship between $\lambda$ and $S_{\mathrm{o}}$ due to either the lack of information regarding $N_{\mathrm{d}}$ (needed to calculate $S_{\mathrm{o}}$ ) or the lack of information regarding the initial aerosol number concentration (needed to calculate $\lambda$ ). As a result, we show the findings from the published literature (Fig. 1) for $\lambda^{\prime}$ as a function of $S_{0}^{\prime}$, where the "prime" denotes that the terms in the axes are not necessarily the same for all points. Specifically, $S_{\mathrm{o}}^{\prime}$ is $\mathrm{d} \ln R / \mathrm{d} \ln N_{\mathrm{a}}$ in Jiang et al. (2010), and $\lambda^{\prime}$ is $\mathrm{d} \ln L W P / \mathrm{d} \ln N_{\mathrm{d}}$ in Berner et al. (2011). For all other references, $\lambda^{\prime}=\lambda$ and $S_{0}^{\prime}=S_{0}$, as defined in Eqs. (1) and (4), respectively.

Because the model output was unavailable from many of these studies, every effort was made to carefully read off the relevant values of LWP, $R$ and $N_{\mathrm{a}}$ (or a similar aerosol measurement, such as the number concentration of cloud condensation nuclei $N_{\mathrm{CCN}}$ or $N_{\mathrm{d}}$ ) from the published figures. Although a consistent methodology was applied to calculate $\lambda^{\prime}$ and $S_{0}^{\prime}$, we make no claims on the accuracy of these results. The main point is to see whether any trends in $\lambda^{\prime}$ vs. $S_{\mathrm{o}}^{\prime}$ emerge from different models and for different environmental conditions. Figure 1 shows substantial variability in the $\lambda^{\prime}-S_{\mathrm{o}}^{\prime}$ relationship. Depending upon which subset of points are selected, one can find a negative slope (e.g., green squares; Wang and Feingold, 2009a), nearly no slope (e.g., red closed circles; Berner et al., 2011), and a positive slope (e.g., blue crosses; Wang and Feingold, 2009a). Interestingly, Wang and Feingold (2009a) suggests either a positive or a negative slope, depending upon how the LWP and $R$ are averaged over the domain (i.e., averaging all of the grid points or conditionally averaging grid points that exceed some predefined threshold).

In the context of Fig. 1, a positive slope corresponds to increasing LWP and decreasing $R$ for an increase in $N_{\mathrm{a}}$. On the other hand, a negative slope corresponds to decreasing LWP and decreasing $R$ for an increase in $N_{\mathrm{a}}$. None of the slopes predicted by the individual high-resolution modeling studies exhibits an intercept near $(0,0)$, and the slopes of these lines tend to be negative or nearly 0 . A more in-depth analysis is clearly warranted.

\subsection{Stratocumulus LES (DYCOMS-II)}

\subsubsection{Rain rates}

The LES results are presented below in the context of three specific thresholds on $R$. These thresholds mimic minimum detectable limits for $R$ from current satellite- and groundbased retrievals. The three values for $T_{\mathrm{h}}$ are $0.001,0.5$, and $5 \mathrm{~mm}$ day $^{-1}$. For perspective, the minimum detectable radar reflectivity $Z$ for CloudSat is $-30 \mathrm{dBZ}$ (e.g., Haynes et al., 2009), while the minimum for the Tropical Rainfall Measuring Mission (TRMM) is $17 \mathrm{dBZ}$. In regard to the CloudSat measurements, $0 \mathrm{dBZ}$ is typically used to define rain, which corresponds to a rain rate of approximately $0.5 \mathrm{~mm}^{-1 a y}{ }^{-1}$. The TRMM reflectivity corresponds to a rain rate of approximately $5 \mathrm{~mm}$ day $^{-1}$. While inherent uncertainties in the $Z-R$ relationships (emanating from, e.g., assumed drop size distributions and attenuation) can contribute to small variations in the lowest detectable rain rates, we use $T_{\mathrm{h}}$ of 0.5 and $5 \mathrm{~mm} \mathrm{day}^{-1}$ to represent CloudSat and TRMM rain rate observations, respectively. Albeit very low, the $0.001 \mathrm{~mm}^{\text {day }}{ }^{-1}$ rain rate threshold is included for a broader perspective and to encompass the range of rain rates presented in Mann et al. (2014).

Before delving into the relative changes in LWP, $R$, and POP, an analysis of the absolute range of $R$ produced in the simulations is informative. Figure 2 depicts the mean (solid) and median (dashed) rain rates for $T_{\mathrm{h}}$ of 0.001 (gray), 0.5 (blue), and 5 (red) $\mathrm{mm} \mathrm{day}^{-1}$ for the DYCOMS-II simulations. The shaded area encompasses the 10th to the 90th percentiles. Figure 2a shows that the average $R$ is approximately 2-6 mm day ${ }^{-1}$ for $T_{\mathrm{h}}$ of 0.001 and $0.5 \mathrm{~mm} \mathrm{day}^{-1}$ and $N_{\mathrm{a}}=25 \mathrm{mg}^{-1}$; the 90th percentile for both thresholds 

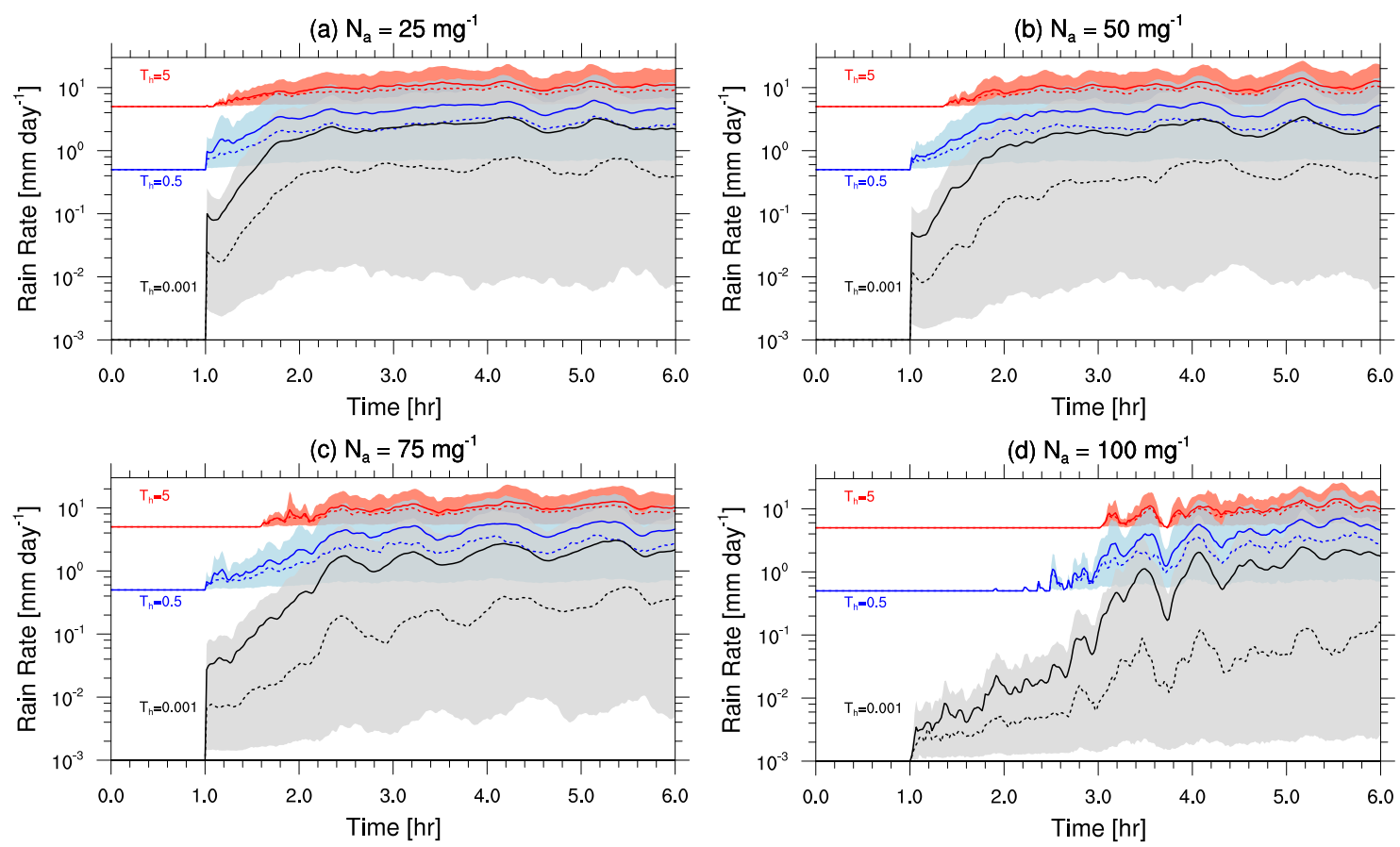

Figure 2. Mean (solid) and median (dashed) rain rates for the three rain rate thresholds $-T_{\mathrm{h}}$ of 0.001 (gray), 0.5 (blue), and 5 (red) mm day ${ }^{-1}$ - for four different aerosol loadings. The shaded region encompasses the 10th percentile to the 90th percentile. $R$ is depicted as equal to $T_{\mathrm{h}}$ for the first hour as a reference point for the minimum $R$ that is possible under each $T_{\mathrm{h}}$ condition. The model output is for the DYCOMS-II case.

is approximately $10 \mathrm{~mm}_{\text {day }}{ }^{-1}$. The $R$ values decrease as $N_{\mathrm{a}}$ increases (Figs. 2b-d).

In general, there is a small increase in the mean and median $R$ as $T_{\mathrm{h}}$ increases from 0.001 to $0.5 \mathrm{~mm} \mathrm{day}^{-1}$; the increase is much more substantial for a further increase in $T_{\mathrm{h}}$ to $5 \mathrm{~mm}$ day $^{-1}$. At this high threshold, the mean $R$ is close to the 90th percentile for $T_{\mathrm{h}}$ of 0.001 and $0.5 \mathrm{~mm} \mathrm{day}^{-1}$; therefore, most of the lightly drizzling grid points are excluded by choosing such a high $T_{\mathrm{h}}$. The importance of these thresholds on $R$ will be discussed in more detail below with respect to incremental increases in $N_{\mathrm{a}}$. Figure 2 excludes the model results for $N_{\mathrm{a}}=125 \mathrm{mg}^{-1}$ because $R$ was too small for all but the smallest $T_{\mathrm{h}}$ to be confident in the average values of POP and $R$.

\subsection{2 $\lambda-S_{\text {pop }}$ relationship and $A_{\mathrm{f}}$}

Figure 3 presents $\lambda$ vs. $S_{\text {pop }}$ for the three different rain rate thresholds (i.e., $T_{\mathrm{h}}$ ). $\lambda$ increases with increasing $S_{\text {pop }}$ for all $T_{\mathrm{h}}$, while the slope tends to decrease as $T_{\mathrm{h}}$ increases, especially when only examining relatively small changes in $N_{\mathrm{a}}$ (i.e., black and red points). In fact, for $T_{\mathrm{h}}=0.001 \mathrm{~mm}^{\text {day }}{ }^{-1}$, $S_{\text {pop }} \simeq 0$ for a change in $N_{\mathrm{a}}$ from 25 to $50 \mathrm{mg}^{-1}$. In these relatively clean conditions, nearly all grid points are precipitating when such a low $T_{\mathrm{h}}$ is used; a small absolute change in $N_{\mathrm{a}}$ is not sufficient to decrease $R$ to the point that $R$ becomes less than $T_{\mathrm{h}}$ for a substantial subset of the domain. Hence, lit- tle if any change is found in POP in response to increases in $N_{\mathrm{a}}$. This finding suggests that for low $T_{\mathrm{h}}$, POP may be largely insensitive to changes in $N_{\mathrm{a}}$ in relatively clean environments containing stratocumulus clouds. However, for higher $T_{\mathrm{h}}$, even in relatively clean conditions, a doubling of $N_{\mathrm{a}}$ produces an increase in $S_{\text {pop }}$ (Fig. 3c) because in these conditions, even a change in $N_{\mathrm{a}}$ from 25 to $50 \mathrm{mg}^{-1}$ is sufficient to reduce $R$ such that $R$ becomes less than $T_{\mathrm{h}}=5 \mathrm{~mm}$ day $^{-1}$ for a substantial subset of the domain.

As mentioned above, $T_{\mathrm{h}}=0.5 \mathrm{~mm}^{-1 a y}{ }^{-1}$ corresponds roughly to the threshold that is commonly used to determine precipitating locations in the CloudSat data set. Higher $T_{\mathrm{h}}$ tends to suppress the LWP response to changes in $N_{\text {a }}$ (i.e., $\lambda$ ) such that the intercept approaches $(0,0)$ as $T_{\mathrm{h}} \longrightarrow 5 \mathrm{~mm}^{-1} \mathrm{y}^{-1}$ for these stratocumulus clouds. Physically, an intercept of $\approx 0$ seems unlikely. Hypothetically, if an increase in $N_{\mathrm{a}}$ results in no change in POP $\left(S_{\text {pop }}=0\right)$, the LWP should increase as the cloud droplets become smaller and more numerous and rain formation becomes less efficient. Therefore, in readily precipitating clouds, one would expect that the LWP should increase in response to increasing $N_{\mathrm{a}}(\lambda>0)$, as suggested in Figs. 3a and b. Both observational studies (Christensen and Stephens, 2011) and LES (e.g., Wang et al., 2003; Ackerman et al., 2004; Xue et al., 2008) have confirmed $\lambda>0$ for readily precipitating clouds. The high-resolution LES results for stratocumulus clouds presented herein suggest that for an observed value of 
(a) $T_{h}=0.001 \mathrm{~mm} \mathrm{day}^{-1}$

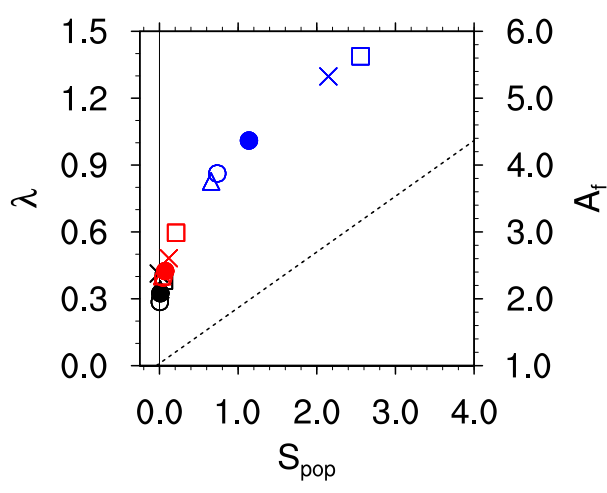

(b) $T_{h}=0.5 \mathrm{~mm} \mathrm{day}^{-1}$

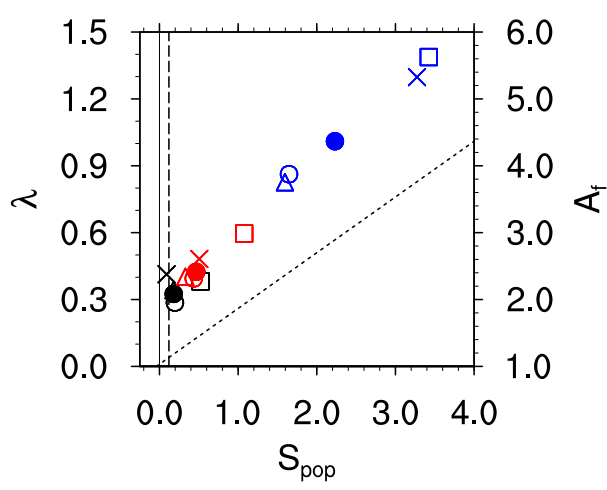

(c) $T_{h}=5 \mathrm{~mm}$ day $^{-1}$

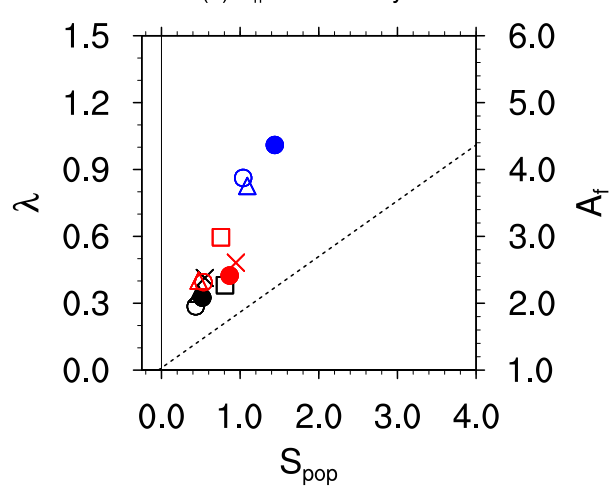

Figure 3. Scatterplot of $\lambda$ (and $A_{\mathrm{f}}$, right axis) vs. $S_{\text {pop }}$ for thresholds $T_{\mathrm{h}}$ of (a) 0.001 , (b) 0.5 , and (c) $5 \mathrm{~mm} \mathrm{day}^{-1}$. These thresholds are representative of the set of 10 thresholds analyzed. Here, the following colors denote changes in $N_{\mathrm{a}}$ from $25 \mathrm{mg}^{-1}$ to $50 \mathrm{mg}^{-1}$ (black), $75 \mathrm{mg}^{-1}$ (red), and $100 \mathrm{mg}^{-1}$ (blue) for the DYCOMS-II case. The symbols signify the control (solid circles), Hi-LHF (open circles), Lo-LHF (crosses), Lo-CC (open squares), and Hi-CC (open triangles) simulations. Note that not all symbols appear, especially for larger changes in $N_{\mathrm{a}}$ and high threshold values, because for those conditions, no points meet the criterion for calculating $\lambda$ and/or $S_{\text {pop }}$. The thin dashed line shows the linear relationship determined by Wang et al. (2012) for the $\lambda-S_{\text {pop }}$ relationship, while the vertical dashed line in (b) corresponds to the satellite-measured value of $S_{\text {pop }}$, i.e., 0.12 (Wang et al., 2012), at a similar $T_{\mathrm{h}}$.
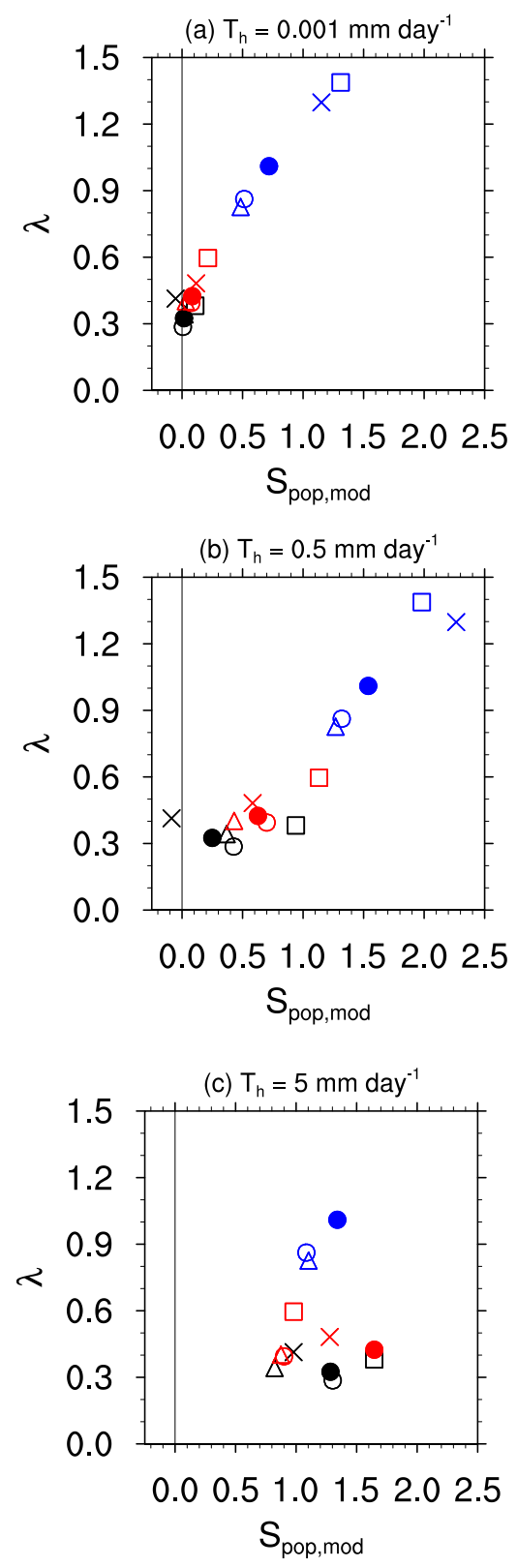

Figure 4. As in Fig. 3 except for $\lambda$ vs. $S_{\text {pop,mod, }}$ i.e., where the denominator in Eq. (3) is $N_{\mathrm{d}}$.

$S_{\text {pop }}=0.12$ (the average global ocean value associated with a $T_{\mathrm{h}}$ of approximately $\left.0.5 \mathrm{~mm} \mathrm{day}^{-1}\right), \lambda$ is approximately 0.3 (Fig. 3b).

Figure 3a suggests that for marine stratocumulus, $\lambda$ is not likely to increase indefinitely as $S_{\text {pop }}$ increases. Instead, an asymptotic behavior is suggested whereby any further increase in $S_{\text {pop }}$ produces a smaller or nearly no change in $\lambda$. It is at this point that the change in $N_{\mathrm{a}}$ is sufficiently large to permit aerosol-induced evaporationentrainment or sedimentation-entrainment effects to play a role. In other words, a further suppression in POP does not 
(a) $T_{h}=0.001 \mathrm{~mm}$ day

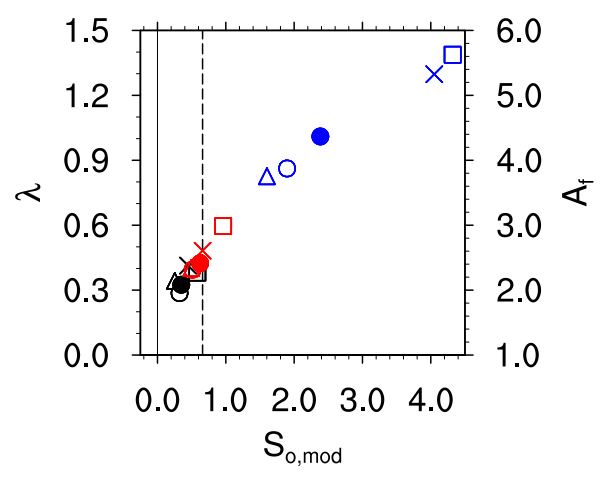

(b) $T_{h}=0.5 \mathrm{~mm}$ day $^{-1}$

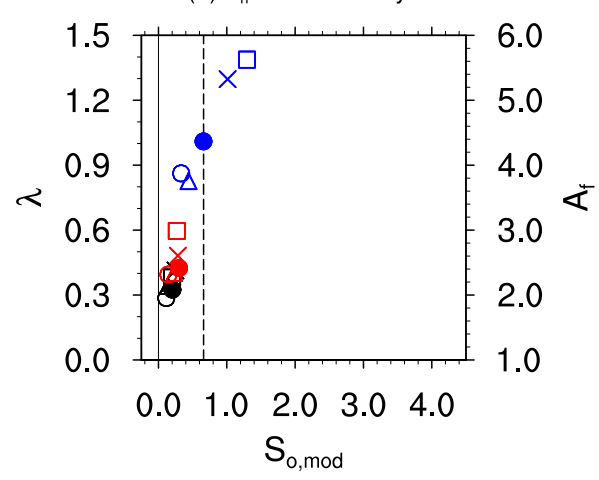

(c) $T_{h}=5 \mathrm{~mm}$ day $^{-1}$

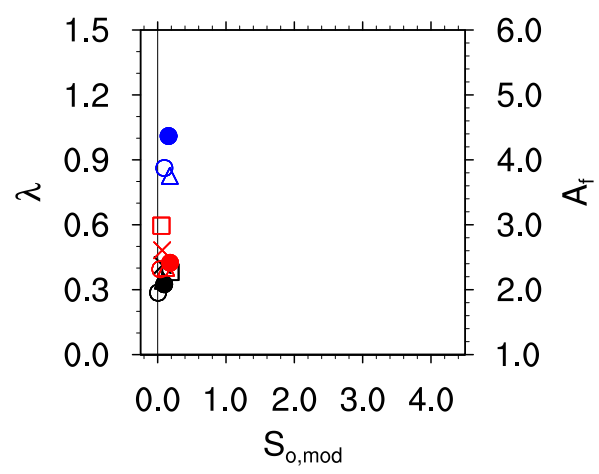

Figure 5. As in Fig. 3 except for $\lambda$ vs. $S_{\text {o, mod }}$, i.e., where the denominators of the $x$ and $y$ axes are the same. The vertical dashed lines in (a) and (b) correspond to the surface remotely measured value of $S_{\mathrm{O}}$, mod, i.e., 0.66 (Mann et al., 2014), which was based on rain rates ranging from approximately 0.002 to $0.5 \mathrm{~mm} \mathrm{day}^{-1}$.

lead to an additional increase in LWP because the much smaller droplets evaporate more readily (e.g., Wang et al., 2003; Ackerman et al., 2004; Xue and Feingold, 2006) or because weaker sedimentation enhances both evaporation and cooling at cloud top, both of which increase entrainment (Bretherton et al., 2007). This asymptotic behavior is challenging to discern for higher $T_{\mathrm{h}}$ due to an insufficient number of points for which $R$ exceeds $T_{\mathrm{h}}$ in the presence of higher aerosol loadings.
The inability of $\lambda$ to increase indefinitely as POP is further reduced should be expected given previously published findings. For example, Ackerman et al. (2004) demonstrated that the LWP first increases with increasing $N_{\mathrm{a}}(\lambda>0)$; further increases in $N_{\mathrm{a}}$ result in $\lambda=0$, and for a strong enough aerosol perturbation, $\lambda$ becomes negative. Under these high aerosol conditions, clouds are likely not precipitating and $\lambda$ is dominated by processes other than collision-coalescence.

Figure 3 also provides a useful estimate of $A_{\mathrm{f}}$ for marine stratocumulus by applying Eq. (11) to the simulated values of $\lambda$. The right axes of the plots in Fig. 3 demonstrate the range of possible $A_{\mathrm{f}}$. For a value of $S_{\text {pop }}$ of 0.12 and $T_{\mathrm{h}}=$ $0.5 \mathrm{~mm} \mathrm{day}^{-1}$, or by simply choosing the results for small changes in $N_{\mathrm{a}}$, the DYCOMS-II RF02 simulations suggest that $A_{\mathrm{f}}$ is approximately 2 , i.e., the albedo susceptibility may be $100 \%$ greater than expected under constant LWP conditions.

\subsection{3 $\lambda-S_{\text {pop,mod }}$ relationship}

Figure 4 shows the relationship between $\lambda$ and $S_{\text {pop,mod }}$, in which the denominators of the terms in the $x$ and $y$ axes are no longer the same. For low $T_{\mathrm{h}}$, changing the denominator has little to no effect on the relationship between relative changes in LWP and POP (Fig. 4a). However, for higher $T_{\mathrm{h}}$, i.e., values that reflect the higher detection limits of satellite retrievals, the inconsistent denominator causes the relationship to become less linear and more scattered, especially for $T_{\mathrm{h}}=5 \mathrm{~mm} \mathrm{day}^{-1}$. The reason for this discrepancy is related to the fact that the relative changes in LWP and POP due to changes in $N_{\mathrm{a}}$ reflect a response due to the prescribed aerosol perturbation, i.e., the changes are relative to only the initial aerosol loading, whereas relative changes in LWP and POP due to changes in $N_{\mathrm{d}}$ reflect the effects of numerous microphysical processes (e.g., activation, collisioncoalescence, and scavenging). Because $N_{\mathrm{d}}$ is not constant in time, the relative change in $N_{\mathrm{d}}$ tends to vary as a function of time. This transient nature produces the scatter in Figs. $4 \mathrm{~b}$ and $\mathrm{c}$.

\subsection{4 $\lambda-S_{0, \text { mod }}$ relationship and $A_{\mathrm{f}}$}

As discussed above, $S_{0}$ is typically represented in terms of relative changes in $N_{\mathrm{d}}$. The previous subsection demonstrated how inconsistencies in the denominator can cause the relationship between $\lambda$ and $S_{\text {pop }}$ to lose its coherency. Therefore, we show the relationship between $\lambda$ and $S_{0 \text {, mod }}$, i.e., where the denominators of the terms in the $x$ and $y$ axes are both a function of the relative change in $N_{\mathrm{a}}$ (Fig. 5). As mentioned in Sect. 3.2.2, small changes in $N_{\mathrm{a}}$ exhibit little to no effect on POP when a low threshold on $R$ is applied to determine raining and non-raining locations. The same does not hold true for $R$, even at low thresholds. $R$ still changes due to increases in aerosol loading, even for small absolute changes. Therefore, the stratocumulus clouds continue to 

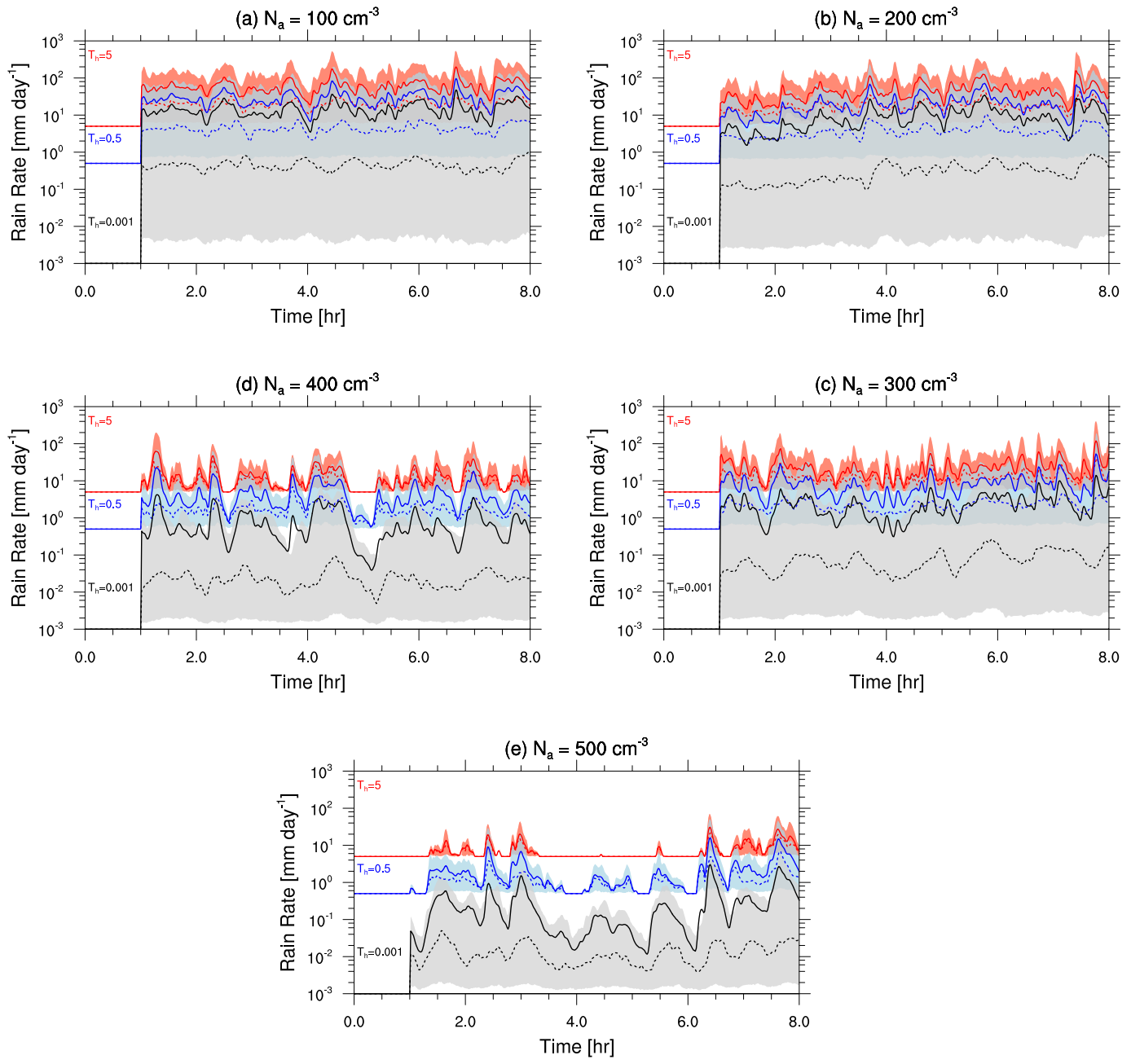

Figure 6. As in Fig. 2 except for the RICO case (the model output is from Jiang et al., 2010).

precipitate throughout most of domain for imposed increases in $N_{\mathrm{a}}$, although the average $R$ is slightly reduced. This effect is demonstrated in Fig. 5a, where we see that $S_{\mathrm{o} \text {, mod }}$ is greater than 0 (unlike the case for $S_{\text {pop }}$, Fig. 3a).

A comparison between Figs. 3 and 5 suggests that the relationships are qualitatively the same (i.e., $\lambda$ tends to increase as either $S_{\text {pop }}$ or $S_{\text {o, mod }}$ increases); however, the slopes can be quite different. The difference in slopes is related to the aforementioned point that changes in $N_{\mathrm{a}}$ act differently on

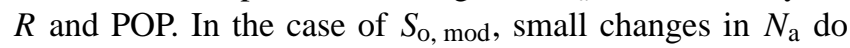
little to affect the average $R$ in the heavily drizzling regions, i.e., the high threshold is inclusive enough to maintain a relatively constant average $R$ for all aerosol perturbations. However, for low $T_{\mathrm{h}}$, nearly the entire domain is considered to be drizzling and a small change in $N_{\mathrm{a}}$ reduces $R$. Because this reduction is not sufficient to convert many drizzling locations into non-drizzling points, $S_{\mathrm{o}}$ increases (Fig. 5a) while $S_{\text {pop }}$ (Fig. 3a) remains nearly constant for small changes in $N_{\mathrm{a}}$.
Using the $S_{\mathrm{o}, \bmod }=0.66$ observational constraint from Mann et al. (2014) (recall that $S_{\mathrm{o}} \approx 1$ for realistic values of c) for this scenario, one arrives at values of $\lambda$ ranging from 0.4 to 1.0 for $T_{\mathrm{h}}=0.001 \mathrm{~mm} \mathrm{day}^{-1}$ and $T_{\mathrm{h}}=0.5 \mathrm{~mm} \mathrm{day}^{-1}$, respectively. For $T_{\mathrm{h}}=5 \mathrm{~mm}$ day $^{-1}$, Fig. $5 \mathrm{c}$ suggests that $\lambda$ would be substantially larger; however, the simulations do not extend to large enough $N_{\mathrm{a}}$ to quantify this effect. Additionally, Mann et al. (2014) did not include rain rates larger than $1 \mathrm{~mm} \mathrm{day}^{-1}$. The right axes in Fig. 5 provide equivalent estimates of $A_{\mathrm{f}}$ derived from Eq. (11), suggesting the potential for enhancements in the albedo susceptibility of 2.5 (4) for $T_{\mathrm{h}}=0.001 \mathrm{~mm} \mathrm{day}^{-1}\left(0.5 \mathrm{~mm} \mathrm{day}^{-1}\right)$.

\subsection{Trade wind cumulus: RICO LES}

\subsubsection{Rain rates}

Figure 6a shows that for $T_{\mathrm{h}}$ of 0.001 and $0.5 \mathrm{~mm}^{-1} \mathrm{yy}^{-1}$ the average $R$ for $N_{\mathrm{a}}=100 \mathrm{~cm}^{-3}$ is approximately 10 $20 \mathrm{~mm} \mathrm{day}^{-1}$ in the simulated trade wind clouds. The domain 

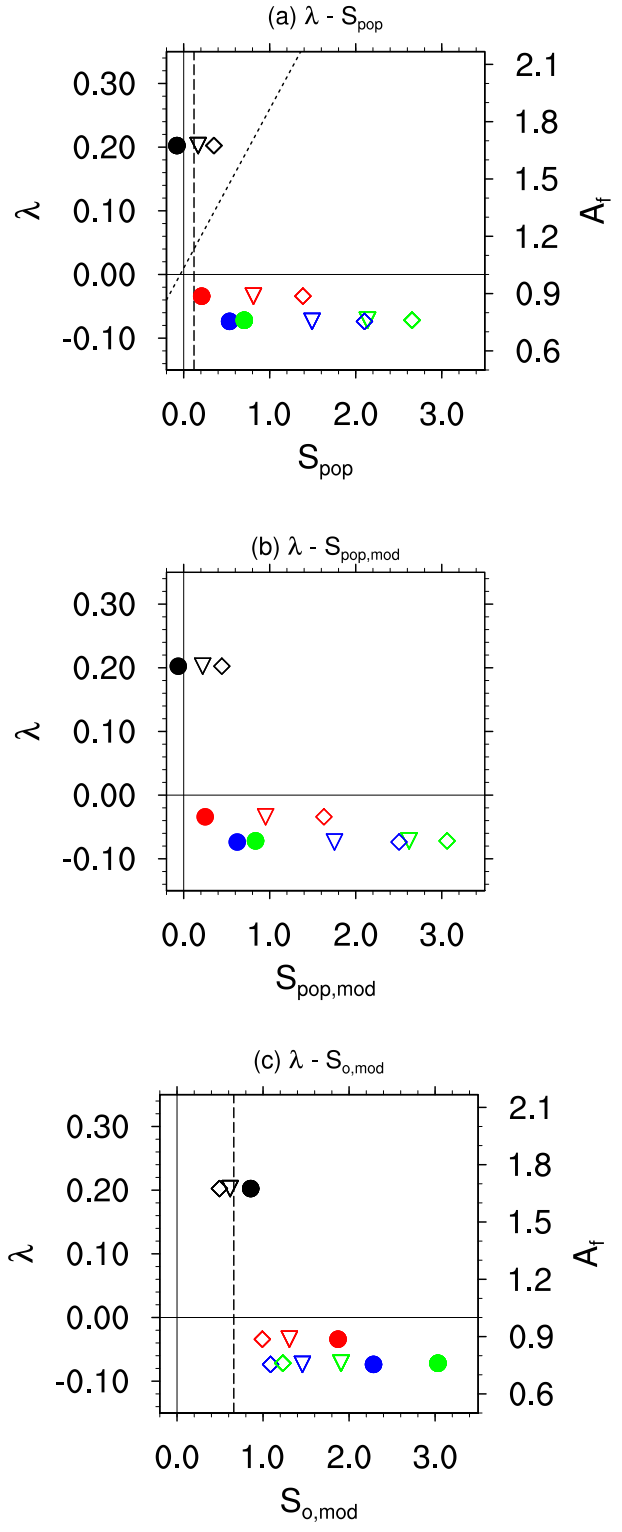

Figure 7. (a) $\lambda$ (and $A_{\mathrm{f}}$ ) vs. $S_{\text {pop }}$, (b) $\lambda$ vs. $S_{\text {pop,mod }}$, and (c) $\lambda$ vs. $S_{\mathrm{o}}$, mod for the RICO simulations from Jiang et al. (2010). The colors correspond to increasing $N_{\mathrm{a}}$ from $100 \mathrm{mg}^{-1}$ to 200 (black), 300 (red), 400 (blue), and 500 (green) $\mathrm{cm}^{-3}$. The symbols denote the different thresholds used to conditionally average $R$ and POP, i.e., $T_{\mathrm{h}}=0.001$ (closed circle), 0.5 (downward-pointing triangle), and 5 (diamond) $\mathrm{mm} \mathrm{day}^{-1}$. In (a), the thin dashed line shows the linear relationship determined by Wang et al. (2012) for the $\lambda-$ $S_{\text {pop }}$ relationship, while the vertical dashed line corresponds to the satellite-measured value of $S_{\text {pop }}$, i.e., 0.12 (Wang et al., 2012). In (c), the vertical dashed line denotes the surface-based estimate of $S_{\text {o, mod }}$, i.e., 0.66 (Mann et al., 2014).

average is naturally much less than this. The average $R$ for all thresholds tends to decrease as $N_{\mathrm{a}}$ increases (Figs. 6be); the largest change occurs when $N_{\mathrm{a}}$ increases from 300 to $400 \mathrm{~cm}^{-3}$ (Figs. $6 \mathrm{c}$ and d). The changes in $R$ for increas-
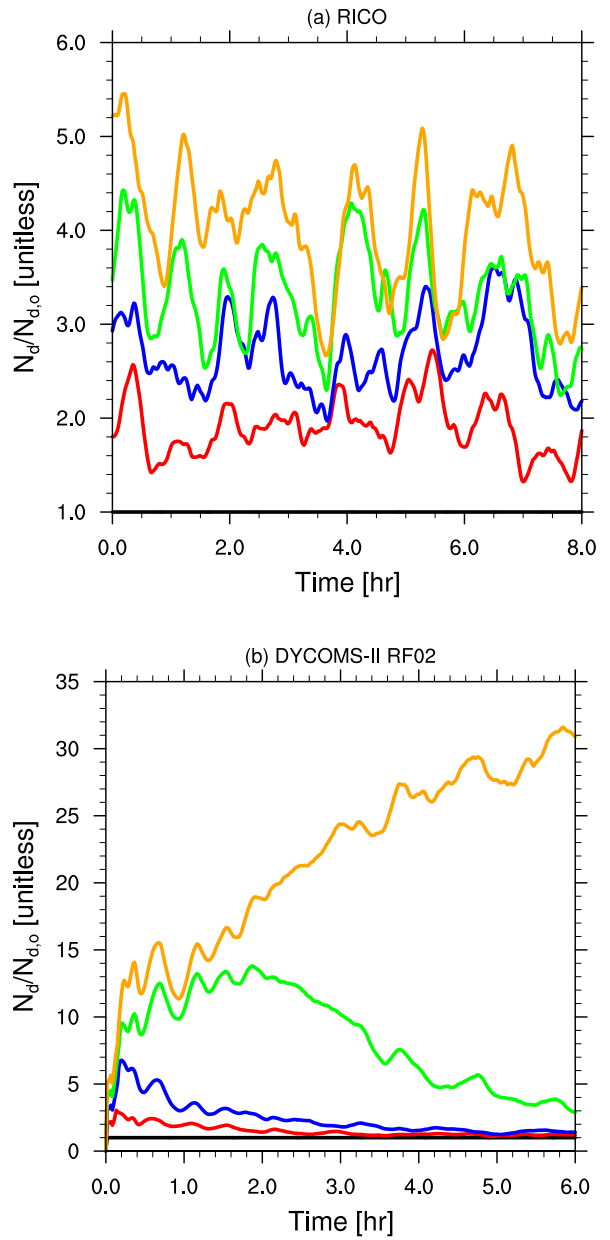

Figure 8. $N_{\mathrm{d}}$ relative to $N_{\mathrm{d}}$ for the lowest aerosol number concentration scenario (i.e., $N_{\mathrm{d}, 0}$ ) for both (a) RICO and (b) DYCOMSII RF02 simulations. Doubling (red), tripling (blue), quadrupling (green), and quintupling (orange) $N_{\mathrm{a}}$ are depicted for both sets of simulations, corresponding to $N_{\mathrm{a}}=200,300,400$, and $500 \mathrm{~cm}^{-3}$ relative to $100 \mathrm{~cm}^{-3}$, respectively, for RICO and $N_{\mathrm{a}}=50,75,100$, and $125 \mathrm{~cm}^{-3}$ relative to $25 \mathrm{~cm}^{-3}$, respectively, for DYCOMS-II RF02.

ing $N_{\mathrm{a}}$ are similar to those shown for the stratocumulus case (Fig. 2) except that $R$ tends to change more rapidly in the trade wind cumulus, especially for higher aerosol loadings. Moreover, Fig. 6 demonstrates that the clouds precipitate for all aerosol loading scenarios and under all threshold values in the RICO case; therefore, the analysis that follows incorporates all five RICO simulations.

\subsection{2 $\lambda-S_{\text {pop }}, S_{\text {pop,mod, }}$ and $S_{\text {o, mod }}$ relationships and $\boldsymbol{A}_{\mathrm{f}}$}

The RICO simulations elicit an important finding that was alluded to earlier, namely that $\lambda$ is not necessarily positive. Figure 7 demonstrates that $\lambda$ is negative for changes in $N_{\mathrm{a}}$ that are a factor of 3 or larger. Moreover, Fig. 7a shows that 


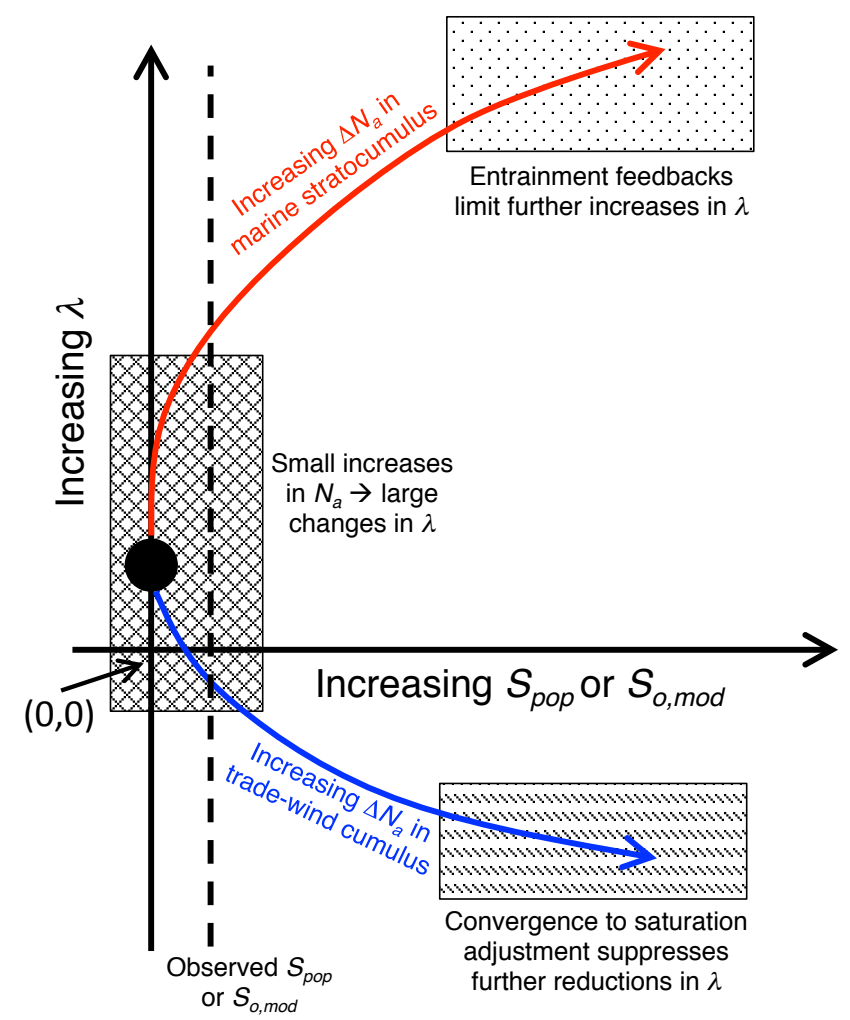

Figure 9. Schematic representation of the results presented herein. The curves correspond to the trajectories in the $\lambda-S_{\text {pop }}$ parameter space for increasing changes in $N_{\mathrm{a}}$ (i.e., $\Delta N_{\mathrm{a}}$ ) in marine stratocumulus (red) and trade wind cumulus (blue). The highlighted regions of the parameter space include areas where further increases in $S_{\text {pop }}$ result in smaller changes in $\lambda$ due to entrainment effects (dotted), where cloud microphysical characteristics asymptote to nearly constant values for larger $\Delta N_{\mathrm{a}}$ (dashed), and where $\lambda$ changes rapidly relative to small changes in $S_{\text {pop }}$ (crossed).

in the case of these shallow trade wind cumulus clouds, $\lambda$ decreases as $S_{\text {pop }}$ increases. This downward trend is related to the balance between aerosol perturbations acting to decrease $R$ on the one hand and to increase entrainment and evaporation of cloud water on the other. The former acts to increase $S_{\text {pop }}$, while the latter decreases $\lambda$. The simulations also suggest that $\lambda$ saturates, as suggested earlier in the case of stratocumulus clouds (Fig. 3). For progressively larger changes in $N_{\mathrm{a}}, S_{\mathrm{pop}}$ continues to increase while $\lambda$ remains relatively constant. This asymptotic behavior results from the fact that the changes in droplet size for increases in aerosol loading beyond $400 \mathrm{~cm}^{-3}$ are small relative to those associated with an increase in $N_{\mathrm{a}}$ from 100 to $200 \mathrm{mg}^{-1}$, which thus limits additional evaporation-entrainment feedbacks on the cloud system. This is analogous to the findings of Xue and Feingold (2006) (Figs. 3 and 5 therein), who showed that several cloud characteristics (e.g., LWP and cloud fraction) asymptote for high aerosol number concentrations. This effect is largely related to the system converging on the saturation adjustment limit, which precludes further decreases in $\lambda$.

The results of the RICO simulations for small changes in $N_{\mathrm{a}}$ (i.e., from 100 to $200 \mathrm{~cm}^{-3}$ ) show that $A_{\mathrm{f}} \approx 1.7$, which happens to be similar to the value of 2 derived for marine stratocumulus based on $S_{\text {pop }}=0.12$ (Fig. 3b). Whereas $A_{\mathrm{f}}$ was shown to increase for larger changes in $N_{\mathrm{a}}$ in marine stratocumulus (Fig. 3), $A_{\mathrm{f}}$ decreases in the case of trade wind cumulus for large enough aerosol perturbations. In this case, the LWP response to an aerosol perturbation acts to decrease the albedo susceptibility $\left(A_{\mathrm{f}}\right.$ is less than 1$)$.

The DYCOMS-II stratocumulus simulations demonstrated that the consistency in the denominator of the terms in the $x$ and $y$ axes is important for increasing the coherency in the $\lambda-$ $S_{\text {pop }}$ or $\lambda-S_{\mathrm{o} \text {, mod }}$ relationships. However, in the trade wind cumulus case, this effect is not noticeable (Figures $7 \mathrm{a}$ and $\mathrm{b}$ are very similar). To explore this further, we consider the relative droplet number concentration $N_{\mathrm{d}} / N_{\mathrm{d}, 0}$, where $N_{\mathrm{d}, 0}$ is the drop concentration associated with the lowest aerosol perturbation simulation. For the trade wind cumulus case, an increase in $N_{\mathrm{a}}$ results in an increase in $N_{\mathrm{d}}$ that does not produce a noticeable trend in $N_{\mathrm{d}} / N_{\mathrm{d}, 0}$ over the course of the $8 \mathrm{~h}$ simulations (Fig. 8a). However, this is not the case for drizzling stratocumulus clouds, where $N_{\mathrm{d}} / N_{\mathrm{d}, 0}$ increases as a result of the efficient removal of aerosol from the domain, especially for the more polluted cases (i.e., $N_{\mathrm{a}}=100$ and $125 \mathrm{mg}^{-1}$; Fig. 8b). The difference is related to the difference in the cloud systems. In the case of trade wind cumulus, only a small fraction of the domain contains condensed cloud water at any given time; therefore, the time required to scavenge a large portion of the ambient aerosol is much longer than in the case of stratocumulus clouds where the cloud fraction is often close to 1 .

Figures $7 \mathrm{a}$ and $\mathrm{b}$ suggest that $\lambda$ decreases more rapidly with increased aerosol loading for lower $T_{\mathrm{h}}$. For $T_{\mathrm{h}}=$ $0.001 \mathrm{~mm} \mathrm{day}^{-1}, \lambda$ decreases from approximately 0.2 to -0.8 for an increase in $S_{\text {pop }}$ of only 0.8 . However, for $T_{\mathrm{h}}=$ $5 \mathrm{~mm} \mathrm{day}^{-1}, \lambda$ decreases from approximately 0.2 to -0.8 for an increase in $S_{\text {pop }}$ of 2.5. This has important implications for constraining $\lambda$ using observations of $S_{\text {pop }}$. For example, if the former trend is true, then small values of $S_{\text {pop }}$ result in small values of $\lambda$. If the latter trend is true, i.e., $\lambda$ decreases gradually with increasing $N_{\mathrm{a}}$ (and increasing $S_{\text {pop }}$ ), then a small value of $S_{\text {pop }}$ implies that $\lambda$ is larger. For reference, if $S_{\text {pop }}$ is 0.12 , then $\lambda$ is approximately 0.2 for $T_{\mathrm{h}}=0.5 \mathrm{~mm} \mathrm{day}^{-1}$ (Fig. 7a, open triangles). Alternatively, if $S_{\mathrm{o}, \bmod }=0.66$ (Mann et al., 2014), then Fig. 7c indicates that $\lambda$ ranges from $0.3\left(T_{\mathrm{h}}=0.001 \mathrm{~mm} \mathrm{day}^{-1}\right)$ to 0.05 $\left(T_{\mathrm{h}}=0.5 \mathrm{~mm} \mathrm{day}^{-1}\right)$. The equivalent range of $A_{\mathrm{f}}$ is 1.2 to 2 . However, for even slightly higher $S_{\mathrm{o} \text {, mod }}$ or $S_{\text {pop }}, \lambda$ quickly becomes negative and $A_{\mathrm{f}}$ becomes less than 1 . 


\section{Conclusions}

Given the difficulty in observationally constraining the LWP response to an increase in aerosol loading $\lambda$, Wang et al. (2012) explored the relationship between $\lambda$ and the precipitation frequency susceptibility $S_{\text {pop }}$ based on a set of climate model simulations. A robust relationship between $\lambda$ and $S_{\text {pop }}$ would provide a useful way to constrain $\lambda$ via $S_{\text {pop }}$ observations. The current work examines this relationship at the large-eddy scale.

First, a review of the literature shows no clear relationship between $\lambda$ and $S_{0}$; these results exhibit little quantitative power given the paucity of the model output from the published studies. To explore this relationship in more detail, a set of large-eddy simulations of a drizzling stratocumulus case is performed, and a previously published set of trade wind cumulus simulations is analyzed. These simulations provide the basis for calculations of both precipitation and albedo susceptibility in an idealized framework for two important shallow cloud regimes.

The following important findings are drawn from this analysis. For brevity, the findings are formulated with respect to $S_{\text {pop }}$; however, the conclusions also apply more generally to $S_{\mathrm{o} \text {, mod. }}$

1. The $y$ intercept of the $\lambda-S_{\text {pop }}$ relationship is likely $>0$ for both stratocumulus and trade wind cumulus cloud systems. This result differs from the global ocean, climate-model-derived $y$ intercept of $\approx 0$ from Wang et al. (2012).

2. $\lambda$ does not necessarily increase linearly as a function of

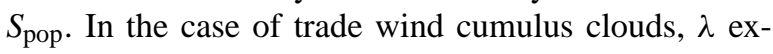
hibits an asymptotic behavior for $S_{\text {pop }}>0.2$ and for all $T_{\mathrm{h}}$; for stratocumulus, the asymptotic behavior is primarily evident at $T_{\mathrm{h}}=0.001 \mathrm{~mm} \mathrm{day}^{-1}$. It is also apparent at $T_{\mathrm{h}}=0.5 \mathrm{~mm} \mathrm{day}^{-1}$ for $S_{\mathrm{o} \text {, mod. For trade wind }}$ cumulus clouds, $\lambda$ is shown to decrease with increasing $S_{\text {pop }}$ due to the effects of entrainment and evaporation (schematically represented in Fig. 9; blue, dotted) and as discussed in Jiang and Feingold (2006) and Small et al. (2009). In the case of stratocumulus clouds, aerosol-induced evaporation-entrainment and/or sedimentation-entrainment effects limit further increases in the LWP (Fig. 9, red, stippled).

3. At the $S_{\text {pop }}=0$ intercept, $\lambda$ is approximately $0.2-0.3$ in both the stratocumulus and trade wind cumulus cases. The simulations suggest that $\lambda$ may increase or decrease with increased aerosol loading (and increasing $S_{\text {pop }}$ ) depending on the cloud type and dominant microphysical processes. These different trends in $\lambda$ are important if one wishes to diagnose $\lambda$ from observations of $S_{\text {pop }}$ or $S_{\mathrm{o} \text {, mod }}$, especially for small aerosol perturbations, which are reflected by larger changes in $\lambda$ and small changes in $S_{\text {pop }}$ (Fig. 9; crossed).
4. To gauge the influence of these results on albedo susceptibility, the fractional enhancement in the albedo susceptibility relative to the value at constant LWP conditions $\left(A_{\mathrm{f}}\right)$ is calculated. For the stratocumulus cloud case, $A_{\mathrm{f}}$ is approximately 2 for a reference observation of $S_{\text {pop }}=$ 0.12 and $T_{\mathrm{h}}=0.5 \mathrm{~mm} \mathrm{day}^{-1}$ (Wang et al., 2012), or approximately 2.5 to 4 if $S_{\mathrm{o}, \bmod }=0.66$ (Mann et al., 2014 ) is the reference observation. In the case of the trade wind cumulus clouds, the values of $A_{\mathrm{f}}$ are 1.2 to 1.5 for $S_{\text {pop }}=0.12$ and 1.7 for $S_{\mathrm{o} \text {, mod }}=0.66$. For slightly higher $S_{\text {pop }}$ or $S_{\mathrm{o} \text {, mod }}$, the albedo susceptibility may actually decrease relative to constant LWP conditions due to the strong leverage of $\lambda$ in Eq. (11). These values are approximate given that solar radiation is not explicitly included in the simulations and because the simulations are relatively short and somewhat idealized. In addition, while the reference observations address either global oceanic clouds (Wang et al., 2012) or a mix of oceanic and continental clouds (Mann et al., 2014), the relative contributions to these data sets of important cloud types, including stratocumulus and trade cumulus, are unknown.

5. The importance of using a consistent denominator in the $\lambda$ and $S_{\text {pop }}$ calculations is demonstrated by calculating $S_{\text {pop }}$ (but not $\lambda$ ) in terms of $N_{\mathrm{d}}$ rather than $N_{\mathrm{a}}$ (i.e., $S_{\text {pop,mod }}$ ). The introduced inconsistency is important in the case of stratocumulus clouds in which $N_{\mathrm{d}}$ decreases (quite rapidly in relatively clean conditions) as a function of time. This effect produces an ill-defined relationship between $\lambda$ and $S_{\text {pop,mod }}$.

6. The slope and intercept of the $\lambda-S_{\text {pop }}$ relationship is largely dependent upon the selected rain rate threshold. This dependency is because determining POP is a binary option, i.e., it is either raining or it is not, which is dependent on some threshold for what is considered "raining".

The current study indicates that the $\lambda-S_{\text {pop }}$ relationship is likely related to the resolution of cloud processes, the scales at which the aerosol interacts with clouds, and the type of system being analyzed (i.e., stratocumulus vs. trade wind cumulus). Based on our earlier work (McComiskey and Feingold, 2012), we surmise that even if convection and aerosolcloud processes are adequately resolved, the $\lambda-S_{\text {pop }}$ relationship will also be dependent on the scale at which the data are aggregated. (The influence of aggregation was also discussed Wang et al., 2012.) More specifically, the true global $\lambda-S_{\text {pop }}$ relationship is an aggregation of local relationships in different cloud and aerosol regimes. Because measurements of $\lambda$ are not practical, a productive avenue would be to pursue regime-based measurements of $S_{\mathrm{pop}}$ or $S_{\mathrm{o} \text {, mod }}$ combined with large-eddy simulations of the type performed here to assess $\lambda$ at a range of scales. The aggregation of these local relationships would provide a more direct comparison with the 
global ocean relationship derived by Wang et al. (2012). A breakdown of GCM results for different cloud regimes would provide an interesting comparison. In conclusion, we caution that these scale, threshold, and aerosol proxy sensitivities be carefully considered before $\lambda-S_{\text {pop }}$ relationships are universally applied.

Acknowledgements. The authors thank the Department of Energy's Atmospheric System Research Program and NOAA's Climate Goal for funding. Hongli Jiang is thanked for providing the RICO simulations.

Edited by: C. Hoose

\section{References}

Ackerman, A. S., Toon, O. B., and Hobbs, P. V.: A model for particle microphysics, turbulent mixing, and radiative transfer in the stratocumulus-topped marine boundary layer and comparisons with measurements, J. Atmos. Sci., 52, 1204-1236, 1995.

Ackerman, A. S., Kirkpatrick, M. P., Stevens, D. E., and Toon, O. B.: The impact of humidity above stratiform clouds on indirect aerosol climate forcing, Nature, 432, 1014-1017, 2004.

Albrecht, B.: Aerosols, cloud microphysics, and fractional cloudiness, Science, 245, 1227-1230, doi:10.1126/science.245.4923.1227, 1989.

Berner, A. H., Bretherton, C. S., and Wood, R.: Large-eddy simulation of mesoscale dynamics and entrainment around a pocket of open cells observed in VOCALS-REx RF06, Atmos. Chem. Phys., 11, 10525-10540, doi:10.5194/acp-11-10525-2011, 2011.

Bréon, F., Tanré, D., and Generoso, S.: Aerosol effect on cloud droplet size monitored from satellite, Science, 295, 834-838, doi:10.1126/science.1066434, 2002.

Bretherton, C. S., Blossey, P. N., and Uchida, J.: Cloud droplet sedimentation, entrainment efficiency, and subtropical stratocumulus albedo, Geophys. Res. Let., 34, doi:10.1029/2006GL027648, 2007.

Christensen, M. W. and Stephens, G. L.: Microphysical and macro physical responses of marine stratocumulus polluted by underlying ships: Eevidence of cloud deepening, J. Geophys. Res., 116, doi:10.1029/2010JD014638, 2011.

Conant, W. C., VanReken, T. M., Rissman, T. A., Varutbangkul, V., Jonsson, H. H., Nenes, A., Jimenez, J. L., Delia, A. E., Bahreini, R., Robets, G. C., Flagan, R. C., and Seinfeld, J. H.: Aerosolcloud drop concentration closure in warm cumulus, J. Geophys. Res., 109, doi:10.1029/2003JD004324, 2004.

Cotton, W. R., Pielke Sr., R. A., Walko, R. L., Liston, G. E., Tremback, C. J., Jiang, H., McAnelly, R. L., Harrington, J. Y., Nicholls, M. E., Carrio, G. G., and McFadden, J. P.: RAMS 2001: Current status and future directions, Meteor. Atmos. Phys., 82, 5-29, doi:10.1007/s00703-001-0584-9, 2003.

Duong, H. T., Sorooshian, A., and Feingold, G.: Investigating potential biases in observed and modeled metrics of aerosol-cloudprecipitation interactions, Atmos. Chem. Phys., 11, 4027-4037, doi:10.5194/aco-11-4027-2011, 2011.

Feingold, G. and Siebert, H.: Cloud-aerosol interactions from the micro to cloud scale, in: Clouds in the perturbed climate sys- tem: their relationship to energy balance, atmospheric dynamics, and precipitation, edited by: Heintzenberg, J. and Charlson, R. J., MIT Press, 2009.

Feingold, G., Stevens, B., Cotton, W. R., and Frisch, A. S.: The relationship between drop incloud residence time and drizzle production in numerically simulated stratocumulus clouds, J. Atmos. Sci., 53, 1108-1122, 1996.

Feingold, G., Boers, R., Stevens, B., and Cotton, W. R.: A modeling study of the effect of drizzle on cloud optical depth and susceptibility, J. Geophys. Res., 102, 13527-13534, doi:10.1029/97JD00963, 1997.

Feingold, G., Walko, R. L., Stevens, B., and Cotton, W. R.: Simulations of marine stratocumulus using a new microphysical parameterization scheme, Atmos. Res., 47, 505-528, 1998.

Feingold, G., McComiskey, A., Rosenfeld, D., and Sorooshian, A.: On the relationship between cloud contact time and precipitation susceptibility to aerosol, J. Geophys. Res., 118, doi:10.1002/jgrd.50819, 2013.

Haynes, J. M., L'Ecuyer, T. S., Stephens, G. L., Miller, S. D., Mitrescu, C., Wood, N. B., and Tanelli, S.: Rainfall retrieval over the ocean with spaceborne W-band radar, J. Geophys. Res., 114, doi:10.1029/2008JD009973, 2009.

Jiang, H. and Feingold, G.: Effect of aerosol on warm convective clouds: Aerosol-cloud-surface flux feedbacks in a new coupled large eddy model, J. Geophys. Res., 11, doi:10.1029/2005JD006138, 2006.

Jiang, H., Feingold, G., and Sorooshian, A.: Effect of aerosol on the susceptibility and efficiency of precipitation in warm trade cumulus clouds, J. Atmos. Sci., 67, 3525-3540, 2010.

Khairoutdinov, M. F. and Randall, D. A.: Cloud resolving modeling of the ARM summer 1997 IOP: Model formulation, results, uncertainties, and sensitivities, J. Atmos. Sci., 60, 607-625, 2003.

L'Ecuyer, T. S., Berg, W., Haynes, J., Lebsock, M., and Takemura, T.: Global observations of aerosol impacts on precipitation occurrence in warm maritime clouds, J. Geophys. Res., 114, doi:10.1002/2008JD011273, 2009.

Lee, S.-S., Feingold, G., and Chuang, P. Y.: Effect of aerosol on cloud-environmental interactions in trade cumulus, J. Atmos. Sci., 69, 3607-3632, doi:10.1175/JAS-D-12-026.1, 2012.

Mann, J. A., Chiu, J. C., Hogan, R. J., O’Connor, E. J., L'Ecuyer, T. S., Stein, T. H. M., and Jefferson, A.: Aerosol impacts on drizzle properties in warm clouds from ARM Mobile Facility maritime and continental deployments, J. Geophys. Res., 119, doi:10.1002/2013JD021339, 2014.

McComiskey, A. and Feingold, G.: Quantifying error in the radiative forcing of the first aerosol indirect effect, Geophys. Res. Lett., 35, doi:10.1029/2007GL032667, 2008.

McComiskey, A. and Feingold, G.: The scale problem in quantifying aerosol indirect effects, Atmos. Chem. Phys., 12, 1031-1049, doi:10.5194/acp-12-1031-2012, 2012.

McComiskey, A., Feingold, G., Frisch, A. S., Turner, D. D., Miller, M. A., Chiu, J. C., Min, Q., and Ogren, J. A.: An assessment of aerosol-cloud interactions in marine stratus clouds based on surface remote sensing, J. Geophys. Res., 114, doi:10.1029/2008JD011006, 2009.

Mitra, S. K., Brinkmann, J., and Pruppacher, H. T.: A wind tunnel study on the drop-to-particle conversion, J. Aerosol Sci., 23, 245-256, 1992. 
Morrison, H. and Gettelman, A.: A new two-moment bulk stratiform cloud microphysics scheme in the community atmosphere model, version 3 (CAM3). Part I: Description and numerical tests, J. Climate, 21, 3642-3659, 2008.

Ogura, Y. and Phillips, N.: Scale analysis of deep and shallow convection in the atmosphere, J. Atmos. Sci., 19, 173-179, 1962.

Platnick, S. and Twomey, S.: Determining the susceptibility of cloud albedo to changes in droplet concentration with the advanced very high resolution radiometer, J. Appl. Meteor. Clim., 33, 334-347, 1994.

Quaas, J., Boucher, O., and Lohmann, U.: Constraining the total aerosol indirect effect in the LMDZ and ECHAM4 GCMs using MODIS satellite data, Atmos. Chem. Phys., 6, 947-955, doi:10.5194/acp-6-947-2006, 2006.

Quaas, J., Ming, Y., Menon, S., Takemura, T., Wang, M., Penner, J. E., Gettelman, A., Lohmann, U., Bellouin, N., Boucher, O., Sayer, A. M., Thomas, G. E., McComiskey, A., Feingold, G., Hoose, C., Kristjánsson, J. E., Liu, X., Balkanski, Y., Donner, L. J., Ginoux, P. A., Stier, P., Grandey, B., Feichter, J., Sednev, I., Bauer, S. E., Koch, D., Grainger, R. G., Kirkevåg, A., Iversen, T., Seland, Ø., Easter, R., Ghan, S. J., Rasch, P. J., Morrison, H., Lamarque, J.-F., Iacono, M. J., Kinne, S., and Schulz, M.: Aerosol indirect effects -general circulation model intercomparison and evaluation with satellite data, Atmos. Chem. Phys., 9, 8697-8717, doi:10.5194/acp-9-8697-2009, 2009.

Shao, H. and Liu, G.: A critical examination of the observed first aerosol indirect effect, J. Atmos. Sci., 66, 1018-1032, 2009.

Skamarock, W. C., Klemp, J. B., Dudhia, J., Gill, D. O., Barker, D. M., Duda, M. G., Huang, X.-Y., Wang, W., and Powers, J. G.: A description of the advanced research WRF Version 3, National Center for Atmospheric Research, Boulder, Colorado, USA, 2008.

Small, J. D., Chuang, P. Y., Feingold, G., and Jiang, H.: Can aerosol decrease cloud lifetime?, Geophys. Res. Lett., 36, L16806, doi:10.1029/2009GL038888, 2009.

Sorooshian, A., Feingold, G., Lebsock, M. D., Jiang, H., and Stephens, G. L.: On the precipitation susceptibility of clouds to aerosol perturbations, Geophys. Res. Lett., 36, doi:10.1029/2009GL038993, 2009.

Stevens, B., Feingold, G., Cotton, W. R., and Walko, R. L.: Elements of the microphysical structure of numerically simulated nonprecipitating stratocumulus, J. Atmos. Sci., 53, 980-1006, 1996.

Stevens, B., Lenschow, D. H., Vali, G., Gerber, H., Bandy, A., Blomquist, B., Brenguier, J., Bretherton, C. S., Burnet, F., Campos, T., Chai, S., Faloona, I., Friesen, D., Haimov, S., Laursen, K., Lilly, D. K., Loehrer, S. M., Malinowski, S. P., Morley, B., Petters, M. D., Rogers, D. C., Russel, L., Savic-Jovcic, V., Snider, J. R., Sraub, D., Szumowski, M. J., Takagi, H., Thornton, D. C., Tschudi, M., Twohy, C., Wetzel, M., and van Zanten, M. C.: Dynamics and Chemistry of Marine Stratocumulus-DYCOMS-II, Bull. Amer. Meteor. Soc., 84, 579-593, doi:10.1175/BAMS-845-579, 2003.
Stevens, B., Moeng, C.-H., Ackerman, A. S., Bretherton, C. S., Chlond, A., De Roode, S., Edwards, J., Golaz, J., Jiang, H., Khairoutdinov, M., Kirkpatrick, M. P., Lewellen, D. C., Lock, A., Muller, F., Stevens, D. E., Whelan, E., and Zhu, P.: Evaluation of large-eddy simulations via observations of nocturnal marine stratocumulus, Mon. Weather Rev., 133, 1443-1462, 2005.

Stevens, D. E., Ackerman, A. S., and Bretherton, C. S.: Effects of domain size and numerical resolution on the simulation of shallow cumulus convection, J. Atmos. Sci., 59, 3285-3301, 2002.

Terai, C. R., Wood, R., Leon, D. C., and Zuidema, P.: Does precipitation susceptibility vary with increasing cloud thickness in marine stratocumulus?, Atmos. Chem. Phys., 12, 4567-4583, doi:10.5194/acp-12-4567-2012, 2012.

Twohy, C. H., Petters, M. D., Snider, J. R., Stevens, B., Tahnk, W., Wetzel, M., Russel, L., and Burnet, F.: Evaluation of the aerosol indirect effect in marine stratocumulus clouds: Droplet number, size, liquid water path, and radiative impact, J. Geophys. Res., 110, doi:10.1029/2004JD005116, 2005.

Twomey, S.: The influence of pollution on the shortwave albedo of clouds, J. Atmos. Sci., 34, 1149-1152, 1977.

Wang, H. and Feingold, G.: Modeling mesoscale cellular structures and drizzle in marine stratocumulus. Part I: Impact of drizzle on the formation and evolution of open cells, J. Atmos. Sci., 66, 3237-3256, 2009a.

Wang, H. and Feingold, G.: Modeling mesoscale cellular structures and drizzle in marine stratocumulus. Part II: The microphysics and dynamics of the boundary region between open and closed cells, J. Atmos. Sci., 66, 3257-3275, 2009b.

Wang, M., Ghan, S., Liu, X., L'Ecuyer, T. S., Zhang, K., Morrison, H., Ovchinnikov, M., Easter, R., Marchand, R., Chand, D. Qian, Y., and Penner, J. E.: Constraining cloud lifetime effects of aerosols using A-Train satellite measurements, Geophys. Res. Lett., 39, doi:10.1029/2012GL052204, 2012.

Wang, S., Wang, Q., and Feinfold, G.: Turbulence, condensation, and liquid water transport in numerically simulated nonprecipitating stratocumulus clouds, J. Atmos. Sci., 60, 262-278, 2003.

Xue, H. and Feingold, G.: Large-eddy simulations of trade wind cumulus: Investigation of aerosol indirect effects, J. Atmos. Sci., 63, 1605-1622, 2006.

Xue, H., Feingold, G., and Stevens, B.: Aerosol effects on clouds, precipitation, and the organization of shallow cumulus convection, J. Atmos. Sci., 65, 392-406, 2008.

Yamaguchi, T. and Feingold, G.: Technical note: Large-eddy simulation of cloudy boundary layer with the Advanced Research WRF model, J. Adv. Model. Earth Syst., 3, doi:10.1029/2012MS000164, 2012. 